\title{
A One-Dimensional (1-D) Three-Region Model for a Bubbling Fluidized-Bed Adsorber
}

\author{
Andrew Lee and David C. Miller* \\ National Energy Technology Laboratory, 3610 Collins Ferry Road, Morgantown, West Virginia, 26507, United States
}

ABSTRACT: A general one-dimensional (1-D), three-region model for a bubbling fluidized-bed adsorber with internal heat exchangers has been developed. The model can predict the hydrodynamics of the bed and provides axial profiles for all temperatures, concentrations, and velocities. The model is computationally fast and flexible and allows for any system of adsorption and desorption reactions to be modeled, making the model applicable to any adsorption process. The model has been implemented in both gPROMS and Aspen Custom Modeler, and the behavior of the model has been verified.

\section{INTRODUCTION}

As part of ongoing research at the U.S. Department of Energy's (DOE) National Energy Technology Laboratory (NETL) into ways to reduce carbon dioxide emissions from fossil fuel power plants, solid sorbents have received a large amount of attention because of their potentially lower cost, relative to other $\mathrm{CO}_{2}$ separation technologies, due to a reduction in energy demands. In order to accelerate the development of carbon capture technologies by industry, the DOE has initiated the Carbon Capture Simulation Initiative (CCSI). CCSI is developing new computational tools to screen alternatives more rapidly, reduce the time for scale-up and troubleshooting new devices and process, and quantify the technical risk in taking technology from laboratory-scale to commercial-scale. The CCSI toolset is being developed and demonstrated around industry challenge problems, the first of which involves the development of a solid sorbent-based capture system.

Fluidized-bed reactors are used extensively in a wide range of chemical processes that rely on reactions between gases and solids. Fluidized beds are used in combustion processes, gasification, fluidized catalytic cracking of hydrocarbons, and chemical synthesis. They are currently being studied for their potential to remove $\mathrm{CO}_{2}$ from flue gas, since they provide good solid-gas contacting and enable effective heat transfer. Historically, scaleup of fluidization processes from bench-scale to industrial-scale processes has required many intermediate scale tests, because the behavior of the system can change considerably between differently sized units. The need for multiple intermediate scale tests makes the scale-up process expensive and time-consuming. Thus, considerable effort has been put into developing predictive models of fluidization systems to aid in the scale-up process.

The term "fluidization" encompasses a broad range of different systems, which can show significantly different hydrodynamic behavior, depending on the dimensions, solid properties, and gas and solid feed rates in the system. Geldart and Abrahamsen ${ }^{1}$ studied the fluidization behavior of a range of different powers, and observed that powders could be classified into four groups based on their behavior. Group A materials, referred to as aeratable materials, consist of fine particles that show a period of uniform expansion of the fluidized bed after fluidization before the formation of bubbles. Group B materials, referenced as sandlike materials, consist of larger particles and begin to show bubbling behavior immediately after fluidization. Group C, or cohesive, materials consist of very fine powders which tend to aggregate due to very strong interparticle forces. Group D particles consist of very large particles, often on the scale of centimeters, which are difficult to fluidize, because of the very high gas velocities required.

The point at which a bed transitions from a packed bed to become fluidized is referred to as the minimum fluidization velocity. At this point, the drag force exerted on a particle in the bed is equal to the weight of the particle, allowing the particles in the bed to "unlock" and begin to move freely around the bed. As the gas velocity is increased above the minimum fluidization velocity, beds of fine particles (Geldart groups A and C) undergo a period of uniform expansion of the bed of solids, ${ }^{2}$ where the bed density decreases as the gas velocity increases. Eventually, there comes a point, referred to as the minimum bubbling velocity, where increasing the gas velocity causes bubbles to begin to form above the distributor plate, and the bed enters what is known as the "bubbling fluidization regime". However, solids that consist of larger particles (Geldart groups B and D) do not show the period of uniform expansion, and in these systems, bubbles begin to form within the bed as soon as the gas velocity exceeds the minimum fluidization velocity of the solids.

As the gas velocity is increased further, the bubbling action continues to become more vigorous until they no longer appear distinct. This is referred to as the turbulent fluidization regime. Many studies have been conducted to characterize the transition between bubbling and turbulent fluidization; these have been reviewed by $\mathrm{Bi}$ et al. ${ }^{3}$ As the gas velocity continues to increase, entrainment becomes more and more significant until it becomes necessary to feed solids continuously into the bottom of the reactor in order to maintain the fluidized bed. At this point, the bed is referred to as a circulating fluidized bed, and the behavior of the bed is dependent on both the gas velocity and the solids

Received: March 30, 2012

Revised: November 15, 2012

Accepted: November 30, 2012

Published: November 30, 2012 
feed rate. Smolders and Baeyens ${ }^{4}$ provided a good review of fluidized beds operating at these high gas velocities.

The hydrodynamics and behavior of fluidized beds vary significantly between the different regimes of fluidization, and no model has yet been developed that can sufficiently represent all the different regimes. In this paper, attention is focused solely on the bubbling and turbulent regimes (i.e., between the onset of bubble formation and the transition to circulating fluidization) and the development of a model of the behavior in these regimes. Several different approaches have been taken in the past to modeling bubbling, and later turbulent, fluidized-bed reactors for a range of different processes. These approaches have ranged from simple scaling relationships ${ }^{5-7}$ to models that attempt to capture the hydrodynamics of the system. ${ }^{2,8-10}$ Many morerecent hydrodynamic models have been developed, such as those of Kunii and Levenspiel, ${ }^{2,11,12}$ Kato and Wen, ${ }^{10}$ and de SouzaSantos. ${ }^{8,13}$ These models have the advantage of being able to capture the important hydrodynamic characteristics of the system, while remaining relatively computationally simple.

With recent increases in computational power and improvements in understanding of computation fluid dynamics (CFD), some researchers have applied CFD simulations to modeling the behavior of fluidized beds. These models have the potential to capture the full hydrodynamic behavior of the fluidized bed, but they are extremely computationally intensive and slow to solve. Because of the computational requirements of CFD simulations, their use is often limited to very small systems or requires a course mesh that may not be able to capture the details of the bed behavior. The large amount of time required to solve these models, generally on the order of weeks, limits their use for process synthesis and optimization tasks, where a large number of simulations need to be run.

\section{MODEL DEVELOPMENT}

In order to develop a model that could be used for process synthesis and optimization, the hydrodynamic modeling approach was chosen, because it provides a good balance between accuracy and the ability to provide predictive results and the computational demands of solving the model. Since hydrodynamic models describe the behavior of the bubbling fluidized bed, in terms of the characteristics of the rising gas bubbles, these models are only strictly applicable in the bubbling fluidization regime, where well-defined bubbles exist within the bed. The point at which bubbles of gas begin to appear within fluidized beds in strongly dependent on the characteristics of the solid particles being fluidized. For larger solid particles (Geldart groups B and D), bubbles begin to form in the bed as soon as the bed becomes fluidized, which occurs when the superficial gas velocity $\left(v_{g}\right)$ exceeds the minimum fluidization velocity $\left(v_{\mathrm{mf}}\right)$ of the particles. However, finer solid particles (Geldart group A) show a period of uniform expansion beyond the minimum fluidization velocity before bubbles begin to form in the bed. The point at which bubbles begin to form is referred to as the minimum bubbling velocity $\left(v_{\mathrm{mb}}\right)$, which is generally less than $4 v_{\mathrm{mf}}{ }^{2,14-1}$ At higher superficial gas velocities, beyond the critical velocity $\left(v_{\mathrm{cr}}\right)$, the fluidized-bed transitions into the turbulent fluidization regime, at which point the distinct bubbles of the bubbling regime are replaced by rapid, transient voids within the bed. ${ }^{2}$ While the fundamental assumptions related to the presence of distinct bubbles existing within the bed are no longer strictly true at this point, several authors have reported the successful use of hydrodynamic models to simulate beds operating within the turbulent fluidization regime, ${ }^{2,13}$ indicating that this model may reasonably approximate the behavior of beds operating with gas velocities up to the transport velocity $\left(v_{\text {tr }}\right)$, indicating the onset of the circulating fluidization regime. However, at gas velocities in excess of the single particle terminal velocity $\left(v_{t}\right)$, entrainment of solids from the bed into the freeboard of the vessel becomes significant and needs to be considered if a model is to be applied to these conditions.

Many different correlations exist to predict the different regime transitions that occur within fluidized beds. The minimum fluidization velocity of a solid can be estimated using the Ergun equation, by determining the gas velocity at which the pressure drop across a bed of solids is equal to the pressure exerted by the weight of the bed. ${ }^{2}$ This results in eq 1 , where $\varepsilon_{\mathrm{mf}}$ is the minimum fluidization voidage of the fluidized solid, $\phi_{s}$ is the sphericity of the solid, $R e_{\mathrm{p}, \mathrm{mf}}$ is the particle Reynolds number at minimum fluidization $\left(R e_{\mathrm{p}, \mathrm{mf}}=d_{\mathrm{p}} v_{\mathrm{m} f} \rho_{g} / \mu_{g}\right)$ and $\mathrm{Ar}$ is the particle Archimedes number $\left(\operatorname{Ar}=d_{p}^{3} \rho_{g}\left(\rho_{s}-\rho_{g}\right) g / \mu_{g}^{2}\right)$.

$$
\frac{1.75}{\varepsilon_{\mathrm{mf}}^{3} \phi_{s}} R e_{\mathrm{p}, \mathrm{mf}}^{2}+\frac{150\left(1-\varepsilon_{\mathrm{mf}}\right)}{\varepsilon_{\mathrm{mf}}^{3} \phi_{s}^{2}} R e_{\mathrm{p}, \mathrm{mf}}=\mathrm{Ar}
$$

Many empirical correlations have been developed to determine the critical and transport velocities of different solids under a wide range of conditions; however, there is often significant disagreement between correlations. $\mathrm{Bi}$ et al. ${ }^{3}$ and Smolders and Baeyens ${ }^{4}$ have published reviews of the different correlations that are available.

Within a fluidized bed operating in the bubbling regime, three distinct regions can be identified within the bed, ${ }^{2}$ which are illustrated in Figure 1. The bulk of the solids within the bed exist

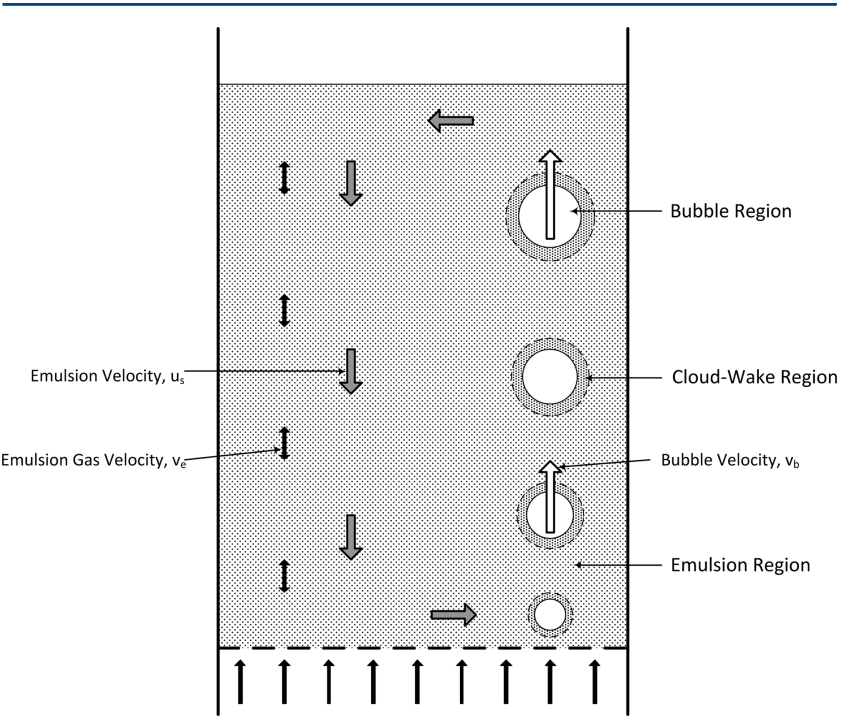

Figure 1. Sketch of the three-region model.

in a dense suspension with the fluidizing gas, at a voidage close to that of a bed at the minimum fluidization velocity. At the bottom of the bed, gas bubbles are formed at the distributor plate through a number of different phenomena determined by the gas velocity and distributor type. These bubbles rise upward through the bed and undergo coalescence and splitting as they rise. As the bubbles rise, they carry with them a circulating cloud of associated gas through which passes some of the suspended solids. Each bubble also carries with it a wake, which is drawn upward behind the bubbles. 
Several different approaches have been taken in developing hydrodynamic models for bubbling fluidized beds. Kunii and Levenspiel $^{2,12}$ used the three-phase approach described above and assumed that the hydrodynamics of the bed could be adequately represented using an average bubble diameter, while Kato and Wen ${ }^{10}$ and Tabis and Essekkat ${ }^{16}$ considered only the emulsion and bubble regions, but allowed for variation in the bubble diameter in the axial direction. In all three cases, the solid phase was assumed to be well-mixed and isothermal, which neglects the effects of axial variations in the condition of the solids. This is especially important in adsorption processes, which can be strongly affected by both temperature and pressure, both of which are likely to vary axially. de Souza-Santos ${ }^{8}$ allowed for axial variations in both the bed hydrodynamics and the solid phase in a full 1-D two-region model for a fluidized-bed combustor. All of these approaches only considered variations occurring in the axial (vertical) direction within the fluidized bed, neglecting any variations in the lateral direction. In any real system, there is likely to be some lateral variation in the conditions of the bed, because of maldistribution of gas and solids, wall effects, feed points, etc.; however, attempting to model these effects would significantly increase the complexity of the model and require solving partial differential equations in two or three dimensions. For large, well-mixed systems with internals to help ensure good distribution of gas and solids, it is hoped that these lateral variations will be minimal and that a $1-\mathrm{D}$ approach to modeling the system will be sufficient.

In this paper, the three-region approach taken by Kunii and Levenspiel $^{2,12}$ is further developed to consider axial variations in the solid phase and the bed hydrodynamics. While Kunii and Levenspiel presented an analytical solution to their model for a simple case of an isothermal bed with a first-order kinetic reaction, ${ }^{12}$ for more-complicated systems, an analytical solution is infeasible. For these systems, it is necessary to develop and solve a set of partial differential equations describing the flow of gas and solids throughout the fluidized bed. Figure 2 shows a diagram of the flows of gas and solids for a differential slice $i$ of the fluidized bed.

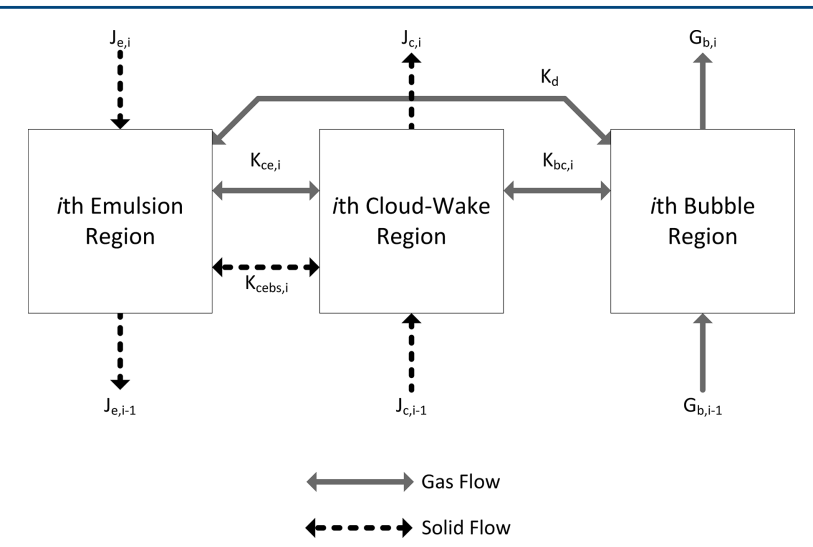

Figure 2. Schematic of the model structure.

In addition to the gas phase heat and mass transfer described by Kunii and Levenspiel, which occurred only between the bubble and cloud-wake and cloud-wake and emulsion regions, ${ }^{2,12}$ an additional bulk flow term was added between the emulsion and bubble regions in the current model. The need for this arose due to the possibility of extremely high reaction rates under some circumstances. This was most apparent at the inlet to the regenerator where heated, heavily loaded sorbent was suddenly contacted by hot gases, resulting in a very rapid desorption of adsorbed $\mathrm{CO}_{2}$. In these situations, it was found that a very large pressure differential was needed between the emulsion and bubble regions (up to $10 \mathrm{~atm}$ in some cases) to achieve the necessary mass transfer between regions relying solely on the bubble motion and diffusive transfer considered by Kunii and Levenspiel. ${ }^{2,12}$ Pressure differentials of this magnitude are clearly unrealistic, and the authors are unaware of any simulated or experimental observations of similar phenomena in the current literature. In order to address this, an empirical bulk flow term was added to the model to allow gas to flow between the emulsion and bubble regions directly.

In an actual bubbling fluidized bed, transfer of gas between the emulsion and bubble regions must occur via the cloud-wake region; however, this would require the addition of two separate bulk flows (emulsion to cloud-wake and cloud-wake to bubble). Because of the very empirical nature of this term in the current model, it was decided to incorporate the bulk flow into a single term, which bypassed the cloud-wake region. This term took a form analogous to Darcy's Law and was governed by the pressure differential between the two regions. While this is clearly not an accurate representation of the actual behavior of these systems, further study of this phenomenon is required in order to develop a better understanding of the process.

At superficial gas velocities significantly greater than the minimum fluidization velocity, the flow rate of gas due to the gas bubbles rising through the bed of solids is much greater than the flow rate of the gas traveling through the emulsion region. Under these circumstances, the flow of gas through the emulsion phase can be safely assumed to be negligible, in comparison to the flow through the bubble region, ${ }^{2}$ which greatly simplifies the model equations. Under these circumstances, it can also be assumed that the axial diffusion of gas will be negligible, in comparison to the bulk flow. Experimental investigation of the bubbles within bubbling fluidized beds has revealed that the bubbles contain $0.2 \%-1 \%$ solids by volume. ${ }^{2}$ While this is a small fraction, it may be significant in situations with rapid kinetics; however, most models for bubbling fluidized beds have neglected the presence of solids in the bubble region. This model will do the same.

As each bubble rises through the bed, it carries with it a significant wake of solids, resulting in an upward flux of solids throughout the bed in the cloud-wake region. Thus, there must also be a corresponding downward flux of solids through the emulsion region to maintain solids within the bed. Additional circulation of solids can be caused by the locations of the solids inlets and outlets to the bed, resulting in a bulk flow of solids in the system. As each bubble rises through the bed, some of the solids in the emulsion region are swept into the cloud surrounding each bubble. Kunii and Levenspiel assumed that all of these solids were then swept into the wake of the bubble to be carried upward through the bed, with an equal amount of solids leaking out of the wake into the emulsion region. ${ }^{2}$ This results in constant mixing of solids between the cloud-wake and emulsion regions throughout the bed.

The current model does not consider the freeboard of the vessel and, thus, neglects any reactions that may occur between gas and solids above the fluidized bed. These are likely to be minimal for beds operating at gas velocities below the single particle terminal velocity, where entrainment of solids into the freeboard is small. However, at higher gas velocities, the presence of solids within the freeboard becomes significant, resulting in 
significant gas-solids interactions in the freeboard. The addition of a model of the freeboard of the vessel is planned for the future.

In any particulate system, there will be some variation in physical properties between individual particles, and the gradual attrition of particles within a contacting process will only amplify these differences. In order to simplify the model equations, it is assumed that the behavior of the fluidized bed can be sufficiently represented using average particle properties and that these are constant throughout the fluidized bed. Because fluidization depends on the interaction between the flowing gas and the solid particle, which is a surface phenomena, a mean surface area should be used to best represent the system. ${ }^{2}$ In addition, for reactive systems, the density of the solid particles may change as the reaction progresses, as may other physical properties of the solid. For the case of adsorption of $\mathrm{CO}_{2}$ by solid sorbents, any changes in the physical properties of the solids will be negligible due to the relatively low loadings of adsorbed species on the sorbent. However, for systems where significant changes in the particle properties are expected to occur, it would be necessary to consider these variations in the model equations.

In order to describe the behavior of a bubbling fluidized-bed reactor, a system of algebraic and differential equations was developed. For a differential slice in the model, mass and energy balances can be written for each phase (gas and solid) and region (bubble, cloud-wake, and emulsion). The axial domain for the model is defined as $x$ with $x=0$ being the bottom of the bed, immediately above the gas distributor plate, and $x=L_{\mathrm{b}}$ being the surface of the fluidized bed of solids (with $L_{\mathrm{b}}$ being the depth of the bed). While it would be possible to extend the model to cover dynamic operations, the current model only considers steadystate operation; thus, all time-dependent terms are set to zero. In developing this model, all rates of reaction were specified in terms of formation of a given species and, for the purposes of heat and mass balances, the reaction between gas and solids is assumed to take place in the solid phase, such that the reaction conditions are those of the solids and any heat of reaction is applied to the solid phase.

Gas-Phase Mass and Energy Balances. For the gas phase, mass balances can be written for each component in the bubble region, which results in eq 2 , where $y_{\mathrm{b}, j, x}$ is the mole fraction of component $j$.

$$
0=-\frac{\partial}{\partial x} y_{\mathrm{b}, j, x} G_{\mathrm{b}, x}-\delta_{x} A_{X} K_{\mathrm{bc}, j, x}\left(C_{\mathrm{b}, j, x}-C_{\mathrm{c}, j, x}\right)+K_{g, \mathrm{bulk}, j, x}
$$

Here, $G_{\mathrm{b}, x}$ is the axial flow rate of gas through the bubble region; $C_{b, j, x}$ and $C_{c, j, x}$ represent the concentrations of component $j$ in the bubble and cloud-wake regions at point $x$, respectively; $\delta_{x}$ is the volume fraction of the bubble region at point $x ; A_{X}$ is the crosssectional area of the bed; $K_{\mathrm{bc}, j, x}$ is the mass-transfer coefficient for component $j$ between the bubble and cloud-wake regions written in terms of bubble volume and $K_{g, b u l k, j, x}$ is the flow rate of component $j$ into the bubble region from the emulsion region due to bulk flow of gas.

The flow rate of gas through the bubble region can be related to the velocity of the gas bubbles, $v_{\mathrm{b}, x}$, and the superficial gas velocity, $v_{g, x}$ as shown in eq 3 .

$$
G_{\mathrm{b}, x}=v_{\mathrm{b}, x} A_{X} \delta_{x} C_{\mathrm{b}, \mathrm{t}, x}=v_{g, x} A_{X} C_{\mathrm{b}, \mathrm{t}, x}
$$

For the cloud-wake region, it is assumed that there is no axial flow of gas; thus, the only terms in the gas-phase mass balance are mass-transfer terms with the other two regions and a reactive term. Here, $\alpha_{x}$ is the cloud-wake to bubble region volume fraction, and $\varepsilon_{\mathrm{d}, x}$ is the voidage fraction of the emulsion region. It is assumed the cloud-wake region has a similar voidage to that of the emulsion region. $K_{\mathrm{ce}, j, x}$ is the mass-transfer coefficient for component $j$ between the cloud-wake and emulsion regions, again written in terms of bubble volume, and $C_{\mathrm{e}, j, x}$ is the concentration of component $j$ is the emulsion region. Finally, $r_{g, c, j, x}$ is the rate of formation of gaseous species $j$ in the cloudwake region due to chemical reaction, expressed on a per volume of solids basis.

$$
\begin{aligned}
0= & \delta_{x} A_{X} K_{b c, j, x}\left(C_{\mathrm{b}, j, x}-C_{c, j, x}\right)-\delta_{x} A_{X} K_{\mathrm{ce}, j, x}\left(C_{\mathrm{c}, j, x}-C_{\mathrm{e}, j, x}\right) \\
& +\alpha_{x} \delta_{x}\left(1-\varepsilon_{\mathrm{d}, x}\right) A_{X} r_{g, \mathrm{c}, j, x}
\end{aligned}
$$

Similarly, a gas-phase mass balance for the emulsion region only contains a term for mass transfer with the cloud-wake region, bulk flow to the bubble region, and a reactive term:

$$
\begin{aligned}
0= & \delta_{x} A_{X} K_{\mathrm{ce}, j, x}\left(C_{\mathrm{c}, j, x}-C_{\mathrm{e}, j, x}\right)-K_{g, \text { bulk }, j, x} \\
& +\left(1-\alpha_{x} \delta_{x}-\delta_{x}\right)\left(1-\varepsilon_{\mathrm{d}, x}\right) A_{X} r_{g, e, j, x}
\end{aligned}
$$

In addition to the mass balance equations, the total gas concentration in each region can be calculated using an equation of state, which must be equal to the sum of the component concentrations in each region.

Energy balances for the gas phase follow in a similar vein to the mass balances, resulting in eqs 6,7 , and 8 .

$$
\begin{aligned}
0= & -\frac{\partial}{\partial x} G_{\mathrm{b}, x} c_{p, g, \mathrm{~b}, x}\left(T_{g, \mathrm{~b}, x}-T_{\mathrm{ref}}\right) \\
& -A_{X} \delta_{x} H_{\mathrm{bc}, x}\left(T_{g, \mathrm{~b}, x}-T_{g, \mathrm{c}, x}\right)+H_{g, \mathrm{bulk}, x} \\
0= & A_{X} \delta_{x} H_{\mathrm{bc}, x}\left(T_{g, \mathrm{~b}, x}-T_{g, \mathrm{c}, x}\right)-A_{X} \delta_{x} H_{\mathrm{ce}, x}\left(T_{g, \mathrm{c}, x}-T_{g, \mathrm{e}, x}\right) \\
& -A_{X} \alpha_{x} \delta_{x}\left(1-\varepsilon_{\mathrm{d}, x}\right) \rho_{s} a_{p} h_{p, x}\left(T_{g, \mathrm{c}, x}-T_{s, c, x}\right) \\
& +\alpha_{x} \delta_{x}\left(1-\varepsilon_{\mathrm{d}, x}\right) A_{X} \sum_{j}\left[r_{g, \mathrm{c}, j, x} c_{p, g, j, \mathrm{c}, x}\left(T_{g, \mathrm{c}, x}-T_{\mathrm{ref}}\right)\right] \\
0= & A_{X} \delta_{x} H_{\mathrm{ce}, x}\left(T_{g, \mathrm{c}, x}-T_{g, \mathrm{e}, x}\right)-H_{g, \mathrm{bulk}, x} \\
& -A_{X}\left(1-\alpha_{x} \delta_{x}-\delta_{x}\right)\left(1-\varepsilon_{\mathrm{d}, x}\right) \rho_{s} a_{p} h_{p, x}\left(T_{g, \mathrm{e}, x}-T_{s, \mathrm{e}, x}\right) \\
& +\left(1-\alpha_{x} \delta_{x}-\delta_{x}\right)\left(1-\varepsilon_{\mathrm{d}, x}\right) A_{X} \\
& \sum_{j}\left[r_{g, \mathrm{e}, j, x} c_{p, g, j, \mathrm{e}, x}\left(T_{g, \mathrm{e}, x}-T_{\mathrm{ref}}\right)\right]
\end{aligned}
$$

Here, $c_{p, g, r, x}$ is the molar specific heat capacity of the gas in region $r$ at point $x ; T_{g, r, x}$ is the temperature of the gas in region $r ; T_{\text {ref }}$ is a thermodynamic reference temperature; $H_{g, \text { bulk, } x}$ is the heat transfer due to the bulk flow of gas from emulsion region to bubble region; and $H_{\mathrm{bc}, x}$ and $H_{\mathrm{ce}, x}$ are the heat-transfer coefficient between the bubble and cloud-wake regions, and between the cloud-wake and emulsion regions, respectively (written in terms of bubble volume). The second-to-last term in the cloud-wake (eq 7) and emulsion region (eq 8) equations represents heat transfer between the gas and solids within each region, where $\rho_{s}$ is the density of the solids, $a_{\mathrm{p}}$ is the mass specific surface area of a particle $\left(\mathrm{m}^{2} / \mathrm{kg}\right), h_{p, x}$ is a heat-transfer coefficient between gas and solid on a surface area basis, and $T_{s, c, x}$ and $T_{s, e, x}$ are the temperature of the solids in the cloud-wake and emulsion regions, respectively. The final term in these equations represents the loss of energy from the gas phase due to mass being 
transferred to the solid phase as part of the reaction, where $c_{p, g, j, c, x}$ and $c_{p, g, j, e, x}$ are the specific molar heat capacities of the gas species $i$ in the cloud-wake and emulsion regions, respectively.

At the gas inlet $(x=0)$, the conditions in the bubble region are given to be the conditions of the incoming gas (flow rate, temperature, and composition). Similarly, the conditions in the gas stream leaving the reactor are equal to the conditions of the bubble phase at the top of the bed $\left(x=L_{\mathrm{b}}\right)$. Gas pressure can be specified either at the inlet or the outlet, depending on the circumstances.

The rate of mass and heat transfer due to the bulk flow of gas is defined by analogy to Darcy's Law and is calculated as shown in eqs 9 and 10 .

$$
\begin{aligned}
& K_{g, \text { bulk }, j, x}=K_{\mathrm{d}}\left(C_{\mathrm{e}, \mathrm{t}, x}-C_{\mathrm{b}, \mathrm{t}, x}\right) y_{*, j, x} \\
& H_{g, \text { bulk }, x}=K_{\mathrm{d}}\left(C_{\mathrm{e}, \mathrm{t}, x}-C_{\mathrm{b}, \mathrm{t}, x}\right) c_{p, g, *, x}\left(T_{g, *, x}-T_{\text {ref }}\right)
\end{aligned}
$$

The temperature and composition of the bulk flow will be dependent on the direction of flow, and $c_{p, g, *, x}, T_{g, *, x}$ and $y_{*, j, x}$ represent the molar specific heat capacity, temperature, and mole fraction of the gas in the region from which the gas is leaving (the emulsion region if $C_{\mathrm{e}, t, x}>C_{\mathrm{b}, t, x} ;$ otherwise, the bubble region). As discussed earlier, $K_{\mathrm{d}}$ is an empirical bulk flow transfer coefficient with units of $\mathrm{m}^{2} \mathrm{~s}^{-1}$, which describes the transfer of gas from the emulsion region to the bubble region due to pressure gradients. $K_{\mathrm{d}}$ is likely to be dependent on the conditions and geometry of the bed, such as the voidage and size of the solid particles. However, to the knowledge of the authors, this phenomenon has not been observed or studied experimentally. Thus, its magnitude and dependence on bed conditions is unknown. For the purposes of this work, it was found that a value of $K_{d}$ on the order of 100 was necessary to reduce the pressure gradients observed in the model to a reasonable level.

Solid Phase Mass and Energy Balances. Although the gas phase can be represented using the same set of equations across the entire fluidized bed, the equations for the solid phase require different conditions at the boundaries of the system and at the solid inlet and outlet. While, in practice, solids can be potentially added and removed from any point within the bed, this model restricts the solids feed and extraction points to either the top of the bed $\left(x=L_{\mathrm{b}}\right)$ or the bottom of the bed $(x=0)$. Thus, the equations at the boundaries of the domain vary, depending on the type of solids inlet and outlet chosen. Equations could be written to allow for solids feed and extraction to occur at any point within the bed by splitting the axial domain at the inlet and outlet points and adding a discontinuity at that point.

Inside the axial domain of the model (anywhere except the two boundaries), the flow of solids must be conserved, which results in eq 11 . Here, $J_{c, x}$ is the upward solids mass flux in the cloudwake region, and $J_{\mathrm{e}, x}$ is the solids mass flux downward in the emulsion region. If both fluxes are defined on a superficial basis, they can be directly equated as shown below:

$$
\frac{\partial J_{c, x}}{\partial x}=\frac{\partial J_{\mathrm{e}, x}}{\partial x}
$$

The upward flux of solids in the cloud-wake region is due to the solids being carried upward in the wake of the bubbles (but not the solids in the cloud surrounding the bubbles) and can thus be directly related to the velocity of the rising bubbles, $v_{\mathrm{b}, x}$, and the volume ratio of the wake to the bubbles, $f_{w}$, as shown in eq $12,{ }^{2}$ based on the density of the solid particles $\rho_{s}$. Similarly, the solids flux in the emulsion region can be used to calculate the downward velocity of the solids in the emulsion region, $u_{s, x}$ as shown in eq 13.

$$
\begin{aligned}
& J_{\mathrm{c}, x}=f_{w} \delta_{x} \rho_{s}\left(1-\varepsilon_{\mathrm{d}, x}\right) v_{\mathrm{b}, x} \\
& J_{\mathrm{e}, x}=\left(1-\alpha_{x} \delta_{x}-\delta_{x}\right) \rho_{s}\left(1-\varepsilon_{\mathrm{d}, x}\right) u_{s, x}
\end{aligned}
$$

As the size, number, and velocity of the gas bubbles change in the axial direction, so too will the amount of solids carried in the wake of the bubbles and, thus, the cloud-wake solids flux $\left(J_{c, x}\right)$. This indicates that there must be a bulk flow of solids between the cloud-wake and emulsion regions. A mass balance for the adsorbed species present in the solids in the cloud-wake region can then be written as shown in eq 14, which contains terms for the axial flow of material through the region, the bulk flow of solids between the cloud-wake and emulsion regions, a term for mixing between the two regions due to the movement of the bubbles and a reactive term. $n_{\mathrm{c}, i, x}$ and $n_{\mathrm{e}, i, x}$ represent the loading of species $i$ (moles of species adsorbed per $\mathrm{kg}$ of sorbent) on the solids in the cloud-wake and emulsion regions, respectively.

$$
\begin{aligned}
0= & -A_{X} \frac{\partial}{\partial x} J_{\mathrm{c}, x} n_{\mathrm{c}, i, x}-K_{s, \mathrm{bulk}, x}-A_{X} \delta_{x} \rho_{s} K_{\mathrm{ce}, \mathrm{b} s, x} \\
& \left(n_{\mathrm{c}, i, x}-n_{\mathrm{e}, i, x}\right)+A_{X} \alpha_{x} \delta_{x}\left(1-\varepsilon_{\mathrm{d}, x}\right) r_{s, \mathrm{c}, i, x}
\end{aligned}
$$

$K_{\mathrm{ce}, \mathrm{b} s, x}$ is a mass-transfer coefficient representing the inter-region mixing relative to the volume of the bubbles (representing the volume of solids transferred per unit volume of bubbles per second), and $r_{s, c, i, x}$ is the rate of formation of species $i$ in the solid phase of the cloud-wake region. A similar mass balance for the emulsion region can also be written as shown in eq 15 .

$$
\begin{aligned}
0= & -A_{X} \frac{\partial}{\partial x} J_{\mathrm{e}, x} n_{\mathrm{e}, i, x}+K_{s, \mathrm{bulk}, x}+A_{X} \delta_{x} \rho_{s} K_{\mathrm{ce}, \mathrm{b} s, x} \\
& \left(n_{\mathrm{c}, i, x}-n_{\mathrm{e}, i, x}\right)+A_{X}\left(1-\alpha_{x} \delta_{x}-\delta_{x}\right)\left(1-\varepsilon_{\mathrm{d}, x}\right) r_{s, \mathrm{e}, i, x}
\end{aligned}
$$

Writing energy balances for the solid phase is more complicated, because of the adsorption of material onto the sorbent. Walton and LeVan ${ }^{17}$ provided a theoretical derivation of the energy balances associated with a fixed-bed adsorption system, which can be extended to apply to fluidized-bed systems. First, the specific enthalpy of the sorbent, including any adsorbed species, must be determined. If a reference state of standard temperature and pressure and zero loading of adsorbed species is used for the solids, then the specific enthalpy of the sorbent plus adsorbed species relative to the reference state, $h_{\text {sorb+ads }}$, can be shown to be $h_{\text {sorb+ads }}=h_{\text {sorb }}+h_{\text {ads }}$, where $h_{\text {sorb }}$ is the specific enthalpy change of the unloaded sorbent and $h_{\text {ads }}$ is the specific enthalpy of the adsorbed species. For the unloaded solid sorbent, assuming that the effect of pressure on the specific enthalpy is negligible, it can be seen that $h_{\text {sorb }}=c_{p, s}\left(T_{s}-T_{\text {ref }}\right)$, where $c_{p, s}$ is the heat capacity of the sorbent. For the adsorbed species, Walton and LeVan calculated the specific enthalpy associated with the adsorbed species using a path analysis; the path analysis began with the adsorbed species in their gaseous state at the reference temperature and pressure after which the temperature and pressure were changed to that of the solid sorbent, followed by adsorption onto the sorbent. ${ }^{17}$ In the current model, the effects of pressure on the relative specific enthalpy can be removed from the calculations, as the reacting gas is already present at the system pressure, and the pressure term will cancel with an equivalent term elsewhere in the energy balance. This results in eq 16 , where $n_{k, r, x}$ is the number of moles involved in reaction $k$ 
adsorbed per kg of sorbent, $a_{k, j}$ is the stoichiometric coefficient for species $j$ in reaction $k, c_{p, j, x}$ is the heat capacity of the species $j$ in the gas phase, and $\Delta H_{\mathrm{rxn}, k}$ is the specific heat of reaction associated with reaction $k$ at the sorbent conditions $\left(T_{s, x}\right.$ and $\left.P_{x}\right)$.

$$
\begin{aligned}
h_{\mathrm{ads}, r, x}= & \sum_{k} n_{k, r, x}\left\{\sum_{j} a_{k, j} c_{p, j, x}\left(T_{s, r, x}-T_{\mathrm{ref}}\right)\right. \\
& \left.+\Delta H_{\mathrm{rxn}, k}\left(T_{s, x}, P_{x}\right)\right\}
\end{aligned}
$$

With the specific enthalpy of the solid phase now defined, energy balances can be written for the solids in both the cloudwake (eq 17) and emulsion regions (eq 18). The energy balances contain one term for each term in the corresponding mass balances, with the fourth term representing the transfer of energy from the gas phase via the reacting gas. Both energy balances also contain a term for gas-solids heat transfer that is equivalent to that in the gas-phase energy balances. The final term in the emulsion region balance accounts for heat transfer to immersed heat exchange tubes within the bed, where $d_{\mathrm{HX}}$ and $N_{\mathrm{HX}}$ are the diameter and number of tubes immersed in the bed respectively, $h_{\mathrm{t}, x}$ is a heat-transfer coefficient between the bed and the tubes based on the area of the tubes, $\Delta T_{\mathrm{HX}, x}$ is the temperature difference between the tubes and the bed, and $C_{r}$ is an empirical constant $\left(C_{r}=1.6\right) .{ }^{18}$ Examination of the energy balances reveals that all of the reference temperature terms cancel out.

$$
\begin{aligned}
0= & -A_{X} \frac{\partial}{\partial x} J_{\mathrm{c}, x}\left[c_{p, s}\left(T_{s, \mathrm{c}, x}-T_{\mathrm{ref}}\right)+h_{\mathrm{ads}, \mathrm{c}, x}\right]-H_{s, \mathrm{bulk}, x} \\
& -A_{X} \delta_{x} \rho_{s} K_{\mathrm{ce}, \mathrm{b} s, x}\left[c_{p, s}\left(T_{s, \mathrm{c}, x}-T_{\mathrm{ref}}\right)+h_{\mathrm{ads}, c, x}\right. \\
& \left.-c_{p, s}\left(T_{s, \mathrm{e}, x}-T_{\mathrm{ref}}\right)-h_{\mathrm{ads}, \mathrm{e}, x}\right]-\alpha_{x} \delta_{x}\left(1-\varepsilon_{\mathrm{d}, x}\right) A_{X} \\
& \sum_{j} r_{g, \mathrm{c}, j, x} c_{p, g, j, \mathrm{c}, x}\left(T_{g, \mathrm{c}, x}-T_{\mathrm{ref}}\right)+A_{X} \alpha_{x} \delta_{x}\left(1-\varepsilon_{\mathrm{d}, x}\right) \rho_{s} a_{p} \\
& h_{p, x}\left(T_{g, \mathrm{c}, x}-T_{s, \mathrm{c}, x}\right) \\
0 & -A_{X} \frac{\partial}{\partial x} J_{\mathrm{e}, x}\left[c_{p, s}\left(T_{s, \mathrm{e}, x}-T_{\mathrm{ref}}\right)+h_{\mathrm{ads}, \mathrm{e}, x}\right]+H_{s, \mathrm{bulk}, x} \\
& +A_{X} \delta_{x} \rho_{s} K_{\mathrm{ce}, \mathrm{b} s, x}\left[c_{p, s}\left(T_{s, \mathrm{c}, x}-T_{\mathrm{ref}}\right)+h_{\mathrm{ads}, \mathrm{c}, x}\right. \\
& \left.-c_{p, s}\left(T_{s, \mathrm{e}, x}-T_{\mathrm{ref}}\right)-h_{\mathrm{ads}, \mathrm{e}, x}\right]-\left(1-\alpha_{x} \delta_{x}-\delta_{x}\right) \\
& \left(1-\varepsilon_{\mathrm{d}, x}\right) A_{X} \sum_{j} r_{g, \mathrm{e}, j, x} c_{p, g, j, \mathrm{e}, x}\left(T_{g, \mathrm{e}, x}-T_{\mathrm{ref}}\right) \\
& +A_{X} \alpha_{x} \delta_{x}\left(1-\varepsilon_{\mathrm{d}, x}\right) \rho_{s} a_{p} h_{p, x}\left(T_{g, \mathrm{c}, x}-T_{s, \mathrm{c}, x}\right)+\pi d_{\mathrm{HX}} h_{t, x} \Delta \\
& T_{\mathrm{HX}, x} N_{\mathrm{HX}} C_{r}
\end{aligned}
$$

The rate of mass and heat transfer due to the bulk solids flow is defined in eqs 19 and 20, where $K_{s, \text { bulk,i,x }}$ is the bulk flow of solid component $i$ at point $x$ and $H_{s, \text { bulk, } x}$ is the bulk flow of energy. The conditions of the solids in the bulk flow will depend on the direction of flow (from the cloud-wake region when $\left(\partial J_{c, x} / \partial x\right)<$ 0 or from the emulsion phase when $\left.\left(\partial J_{c, x} / \partial x\right)>0\right)$. The parameters $n_{*, i, x}$ and $T_{s, *, x}$ are the loading of component $i$ and temperature of the solid in the source region, respectively.

$$
\begin{aligned}
& K_{s, \text { bulk }, i, x}=-A_{X} \frac{\partial J_{c, x}}{\partial x} n_{*, i, x} \\
& H_{s, \text { bulk }, x}=-A_{X} \frac{\partial J_{c, x}}{\partial x}\left(c_{p, s}\left(T_{s, *, x}-T_{\text {ref }}\right)+h_{\text {ads },{ }^{*}, x}\right)
\end{aligned}
$$

The solid phase mass and energy balances at the bottom of the bed $(x=0)$ (immediately above the distributor plate) are given in eqs 21-23 and include terms for the addition and removal of solids through an inlet or outlet. Here, $F_{\text {sorb,in }, 0}$ is the mass flow rate of solids being fed at the bottom of the bed and $F_{\text {sorb,underflow }}$ is the mass flow rate of solids leaving through the underflow exit (equal to zero if no solid feed or exit is present, respectively). $n_{i, \text { in }}$ and $T_{s, \text { in }}$ are the component loadings and temperature of the feed sorbent, respectively.

$$
\begin{aligned}
& J_{\mathrm{e}, 0} A_{X}+F_{\text {sorb }, \text { in }, 0}=J_{\mathrm{c}, 0} A_{X}+F_{\text {sorb }, \text { underflow }} \\
& n_{\mathrm{e}, i, 0} J_{\mathrm{e}, 0} A_{X}+n_{i, \text { in }} F_{\text {sorb }, \text { in }, 0}=n_{\mathrm{c}, i, 0} J_{\mathrm{c}, 0} A_{X}+n_{\mathrm{e}, i, 0} F_{\text {sorb }, \text { underflow }} \\
& J_{\mathrm{e}, 0} A_{X}\left[c_{p, s}\left(T_{s, \mathrm{e}, 0}-T_{\mathrm{ref}}\right)+h_{\mathrm{ads}, e, 0}\right]+F_{\text {sorb }, \text { in }, 0} \\
& \quad\left[c_{p, s}\left(T_{s, \text { in }}-T_{\mathrm{ref}}\right)+h_{\mathrm{ads}, \mathrm{in}}\right] \\
& =J_{c, 0} A_{X}\left[c_{p, s}\left(T_{s, \mathrm{c}, 0}-T_{\mathrm{ref}}\right)+h_{\mathrm{ads}, \mathrm{c}, 0}\right]+F_{\text {sorb }, \text { underflow }} \\
& \quad\left[c_{p, s}\left(T_{s, \mathrm{e}, 0}-T_{\mathrm{ref}}\right)+h_{\mathrm{ads}, e, 0}\right]
\end{aligned}
$$

Similarly, eqs 24-26 give the mass and energy balances at the top of the bed $\left(x=L_{b}\right)$.

$$
\begin{aligned}
& F_{\text {sorb }, \text { in }, L_{\mathrm{b}}}+J_{\mathrm{c}, L_{\mathrm{b}}} A_{X}=J_{\mathrm{e}, L_{\mathrm{b}}} A_{X}+F_{\text {sorb }, \text { overflow }} \\
& n_{\mathrm{c}, j, L_{\mathrm{b}}} J_{c, L_{\mathrm{b}}} A_{X}+n_{i, \text { in }} F_{\text {sorb,in, } L_{\mathrm{b}}} \\
& =n_{\mathrm{e}, j, L_{\mathrm{b}}, L_{\mathrm{b}}} A_{X}+n_{\mathrm{e}, j, L_{\mathrm{b}}} F_{\text {sorb }, \text { overflow }} \\
& J_{\mathrm{c}, L_{\mathrm{b}}} A_{X}\left[c_{p, s}\left(T_{s, \mathrm{c}, L_{\mathrm{b}}}-T_{\mathrm{ref}}\right)+h_{\mathrm{ads}, \mathrm{c}, L_{\mathrm{b}}}\right]+F_{\text {sorb }, \text { in }, L_{\mathrm{b}}} \\
& \quad\left[c_{p, s}\left(T_{s, \mathrm{c}, \text { in }}-T_{\mathrm{ref}}\right)+h_{\mathrm{ads}, \mathrm{c}, \text { in }}\right] \\
& =J_{\mathrm{e}, L_{\mathrm{b}}} A_{X}\left[c_{p, s}\left(T_{s, \mathrm{e}, L_{\mathrm{b}}}-T_{\mathrm{ref}}\right)+h_{\mathrm{ads}, \mathrm{e}, L_{\mathrm{b}}}\right]+F_{\text {sorb }, \text { overflow }} \\
& \quad\left[c_{p, s}\left(T_{s, \mathrm{e}, L_{\mathrm{b}}}-T_{\mathrm{ref}}\right)+h_{\mathrm{ads}, \mathrm{e}, L_{\mathrm{b}}}\right]
\end{aligned}
$$

As can be seen from the above equations, the solids leaving the bed are assumed to be drawn entirely from the emulsion region; thus, the conditions of the exiting solids are the same as those of the emulsion region from which they are withdrawn.

Hydrodynamic Model. The mass and energy balance equations described above provide a description of the flow of material and solids throughout the different phases of the bed; however, solving these equations is dependent on having correlations for the various heat- and mass-transfer coefficients and hydrodynamic properties of the bed. The hydrodynamic modeling approach used in this paper to predict the heat- and mass-transfer coefficients is dependent on predicting the size, velocity, and volume fraction of the rising gas bubbles within the bed as well as the voidage fraction of the cloud-wake and emulsion regions; thus, correlations are needed to describe these characteristics of the bed. The following section describes the correlations used within the current model to predict these properties of the fluidized bed.

Kunii and Levenspiel assumed that the hydrodynamics of the bed could be adequately represented using a mean bubble size; ${ }^{12}$ however, several different correlations have been developed to calculate the size of a bubble as a function of depth within a fluidized bed. Horio and Nonaka ${ }^{19}$ developed one such correlation based on the observation that bubbles undergo both coalescence and splitting as they pass through the bed and 
the understanding that the growth rate of a bubble is determined by the balance of the rates of coalescence and splitting. In order to calculate the diameter of the gas bubbles, Horio and Nonaka used the correlations of Mori and $\mathrm{Wen}^{20}$ to determine the initial diameter of a bubble as it forms above the distributor plate, $d_{\mathrm{b}, 0}$, and the maximum achievable size of a bubble due to coalescence, $d_{\mathrm{b}, \mathrm{m}}$. The correlations of Mori and Wen are shown in eqs 27 and 28 , where $a_{0}$ is the cross-sectional area of the distributor plate per orifice and $v_{\mathrm{e}, x}$ is the gas velocity in the emulsion region.

$$
\begin{aligned}
& d_{\mathrm{b}, 0}=1.38 g^{-0.2}\left(a_{0}\left[v_{g, 0}-v_{\mathrm{e}, 0}\right]\right)^{0.4} \\
& d_{\mathrm{b}, \mathrm{m}, x}=2.59 g^{-0.2}\left(A_{X}\left[v_{g, x}-v_{\mathrm{e}, x}\right]\right)^{0.4}
\end{aligned}
$$

Horio and Nonaka ${ }^{19}$ calculated the equilibrium size of a bubble, taking into account both coalescence and splitting, to be

$$
d_{\mathrm{b}, \mathrm{e}, x}=\frac{D_{\mathrm{t}}}{4}\left(-\gamma_{1}+\gamma_{3, x}\right)^{2}
$$

where $\gamma_{1}=\left[\left(2.56 \times 10^{-2}\right) / v_{\mathrm{mf}}\right]\left(D_{\mathrm{t}} / g\right)^{1 / 2}$ and $\gamma_{3, x}=\gamma_{1}^{2}+4\left(d_{\mathrm{b}, \mathrm{m}, x} /\right.$ $\left.D_{\mathrm{t}}\right)^{1 / 2}$ are parameters from the work of Mori and Wen and $D_{\mathrm{t}}$ is the diameter of the fluidized bed. Horio and Nonaka ${ }^{19}$ then suggested that the diameter of a bubble at a given height within a fluidized bed in the absence of any internals to the reactor, $d_{\mathrm{b}, \mathrm{u}, x}$, could be calculated by eq 30 , where $\gamma_{2, x}=\left(D_{t} / 4\right)\left(\gamma_{1}+\gamma_{3, x}\right)^{2}$. Horio and Nonaka validated their model for both Geldart Group A and Group B materials. ${ }^{19}$

$$
\begin{aligned}
& \left(\frac{\sqrt{d_{\mathrm{b}, \mathrm{u}, x}}-\sqrt{d_{\mathrm{b}, \mathrm{e}, x}}}{\sqrt{d_{\mathrm{b}, 0}}-\sqrt{d_{\mathrm{b}, \mathrm{e}, x}}}\right)^{\left(1-\gamma_{1} / \gamma_{3, x}\right)}\left(\frac{\sqrt{d_{\mathrm{b}, \mathrm{u}, x}}-\sqrt{\gamma_{2, x}}}{\sqrt{d_{\mathrm{b}, 0}}-\sqrt{\gamma_{2, x}}}\right)^{\left(1+\gamma_{1} / \gamma_{3, x}\right)} \\
& =\mathrm{e}^{\left(-0.3 x / D_{t}\right)}
\end{aligned}
$$

In a fluidized bed with internals, such as heat exchanger tubes, the maximum size a bubble can obtain may be constrained by the spacing of the internals. In these situations, Kunii and Levenspiel $^{2}$ suggest that the maximum size of the bubbles is restricted by the hydraulic diameter of the vessel, which is defined as four times the ratio of the cross-sectional area of the fluidized bed to the wetted diameter of the vessel and internal, as shown in eq 31 .

$$
D_{\mathrm{t}, \mathrm{h}}=\frac{4 A_{X}}{\pi\left(D_{\mathrm{t}}+d_{\mathrm{HX}} N_{\mathrm{HX}}\right)}
$$

In this case, the actual size of the rising bubbles $\left(d_{\mathrm{b}, x}\right)$ is assumed to be the smaller of $d_{\mathrm{b}, \mathrm{u}, x}$ calculated using eq 30 and the hydraulic diameter, $D_{\mathrm{t}, \mathrm{h}}$, calculated using eq 31 . The diameter of the fluidized bed can be calculated from the cross-sectional area of the bed plus the cross-sectional area of any internals. Assuming a circular cross-section gives eq 32 :

$$
\pi\left(\frac{D_{\mathrm{t}}^{2}}{4}\right)=A_{X}+\pi\left(\frac{d_{\mathrm{NX}}^{2}}{4}\right) N_{\mathrm{NX}}
$$

In studying the behavior of the bubbles within a bubbling fluidized-bed reactor, several researchers have noted that the velocity of the rising bubbles seems to be correlated to the size of the bubbles, as well as the gas velocity and size of the bed. In order to calculate the velocity of the rising bubbles, Kunii and Levenspiel $^{2,12}$ proposed a set of correlations based on the experiments of Hilligardt and Werther. ${ }^{21}$ Hilligardt and Werther observed that the behavior of the bubbles differed between different types of particles based on their Geldart classification; ${ }^{21}$ thus, it is necessary to determine the classification of the particles. Most bubbling fluidized beds use particles belonging to Geldart group A or B, and Yang ${ }^{22}$ suggested the criteria of Grace ${ }^{23}$ for determining the transition from Group A to Group B materials, with Group A particles having

$$
\operatorname{Ar}=\frac{d_{p}^{3} \rho_{g}\left(\rho_{s}-\rho_{g}\right) g}{\mu_{g}^{2}}<1.03 \times 10^{6}\left(\frac{\rho_{s}-\rho_{g}}{\rho_{g}}\right)^{-1.275}
$$

The correlations proposed by Kunii and Levenspiel are given in eq 34 for Group A materials and eq 35 for Group B materials. For situations where the bubbles are restricted by the hydraulic diameter of the vessel, Kunii and Levenspiel suggest using eq 36 for slugging beds instead. ${ }^{2}$ The experiments of Hilligardt and Werther were performed using three small pilot-scale apparatuses, with diameters up to $1 \mathrm{~m}$; thus, these correlations have only been tested in units up to this size. While many industrial fluidized beds are larger than this, the hydraulic diameters are often much smaller due to the presence of internals within the bed.

Group A materials:

$$
\begin{aligned}
v_{\mathrm{b}, x}= & 1.55\left[v_{g, x}-v_{\mathrm{mf}}+14.1\left(d_{\mathrm{b}, x}+0.005\right)\right] D_{\mathrm{t}, \mathrm{h}}^{0.32} \\
& +0.711 \sqrt{g d_{\mathrm{b}, x}}
\end{aligned}
$$

Group B materials:

$$
v_{\mathrm{b}, x}=1.6\left(v_{g, x}-v_{\mathrm{mf}}+1.13 d_{\mathrm{b}, x}^{0.5}\right) D_{\mathrm{t}, \mathrm{h}}^{1.352}+0.711 \sqrt{g d_{\mathrm{b}, x}}
$$

Slugging Flow:

$$
v_{\mathrm{b}, x}=v_{g, x}-v_{\mathrm{mf}}+0.35 \sqrt{g D_{\mathrm{t}, \mathrm{h}}}
$$

While early models for fluidization assumed that the emulsion region remained at minimum fluidization conditions, ${ }^{9}$ subsequent research indicated that this was not the case. Abrahamsen and Geldart ${ }^{1}$ developed correlations describing the voidage, $\varepsilon_{d, x}$, and gas velocity, $v_{\mathrm{e}, x}$, through the emulsion region of fluidized beds of Geldart group A particles. Their work revealed that the behavior of the emulsion region was strongly dependent on the fraction of fine solids $(<45 \mu \mathrm{m})$ present in the solids $(F)$, as shown in eqs 37 and 38 .

$$
\begin{aligned}
& \frac{1-\varepsilon_{\mathrm{mf}}}{1-\varepsilon_{\mathrm{d}, x}}=\frac{2.54 \rho_{g, x}{ }^{0.016} \mu_{g, x}{ }^{0.066} \mathrm{e}^{0.09 F}}{d_{p}^{0.1} g^{0.118}\left(\rho_{s}-\rho_{g, x}\right)^{0.118} x^{0.043}} \\
& \frac{v_{\mathrm{e}, x}}{v_{\mathrm{mf}}}=\frac{188 \rho_{g, x}{ }^{0.089} \mu_{g, x}{ }^{0.371} \mathrm{e}^{0.508 F}}{d_{p}{ }^{0.568} g^{0.663}\left(\rho_{s}-\rho_{g, x}\right)^{0.663} x^{0.244}}
\end{aligned}
$$

Abrahamsen and Geldart did not study larger Group B and D particles; however, Hilligardt and Werther ${ }^{24}$ reported that the gas velocity in the emulsion phase did not vary appreciable with height for these materials and could be correlated using eq 39:

$$
\frac{v_{\mathrm{e}}-v_{\mathrm{mf}}}{v_{\mathrm{g}}-v_{\mathrm{mf}}}=\frac{1}{3}
$$

Other researchers have suggested that the emulsion region remains much closer to minimum fluidization conditions for course particles. Thus, minimum fluidization conditions can be assumed under these conditions (i.e., $\varepsilon_{\mathrm{d}} \approx \varepsilon_{\mathrm{mf}}$ ). 
It is also necessary to determine the ratio of the volume of the cloud-wake region to the bubble region $\left(\alpha_{x}\right)$. Kunii and Levenspiel $^{2}$ suggested that the volume of the ratio of the volume of the cloud surrounding a bubble to the volume of a bubble can be calculated using the equation

$$
f_{\mathrm{c}, x}=\frac{3 v_{\mathrm{mf}} / \varepsilon_{\mathrm{mf}}}{0.711 \sqrt{g d_{\mathrm{b}, x}}-v_{\mathrm{mf}} / \varepsilon_{\mathrm{mf}}}
$$

while Rowe and Partridge ${ }^{25}$ presented the experimental measurements of the wake-to-bubble volume ratio $\left(f_{w}\right)$. Thus, $\alpha_{x}$ can be calculated using eq 40 with a value of $f_{w}$ taken from Rowe and Partridge. ${ }^{25}$

$$
\alpha_{x}=\frac{3 v_{\mathrm{mf}} / \varepsilon_{\mathrm{mf}}}{0.711 \sqrt{g d_{\mathrm{b}, x}}-v_{\mathrm{mf}} / \varepsilon_{\mathrm{mf}}}+f_{\mathrm{w}}
$$

Heat- and Mass-Transfer Coefficients. Using the bubble characteristics discussed above, Kunii and Levenspiel ${ }^{2}$ developed expressions for the heat- and mass-transfer coefficients between the different regions in the bed based on the behavior of an isolated bubble, as predicted by Davidson and Harrison. ${ }^{9}$ However, experiments by Sit and Grace ${ }^{26}$ on pilot-scale beds suggest that the model proposed by Kunii and Levenspiel underpredicts the actual rates of gas phase mass transfer when rising bubbles interact with each other. Sit and Grace suggested that this was due to an increase in the convective component of the heat- and mass-transfer coefficients and suggested the addition of a correction factor to account for this. ${ }^{26}$ Since the heat- and mass-transfer behavior is closely linked to the movement of the bubbles through the bed, Kunii and Levenspiel expressed all their transfer coefficients in terms of the volume of the bubble region within the model.

For gas-phase mass transfer between the bubbles and their associated clouds, Sit and Grace proposed that the mass-transfer coefficient could be calculated using eq 41, based on the work of Kunii and Levenspiel. ${ }^{2}$ Here, the factor 1.32 is the correction factor proposed by Sit and Grace, ${ }^{26}$ and $D_{j, x}$ is the diffusion coefficient for component $j$ at point $x$.

$$
K_{\mathrm{bc}, j, x}=1.32 \times 4.5\left(\frac{v_{\mathrm{mf}}}{d_{\mathrm{b}, x}}\right)+5.85\left(\frac{D_{j, x}{ }^{0.5} g^{0.25}}{d_{\mathrm{b}, x}{ }^{5 / 4}}\right)
$$

For gas-phase mass transfer between the clouds and the surrounding emulsion, Kunii and Levenspiel proposed that the mass-transfer coefficient could be calculated using eq $42 .^{2}$

$$
K_{\mathrm{ce}, j, x}=6.78 \sqrt{\frac{\varepsilon_{\mathrm{d}, x}^{2} D_{j, x} v_{\mathrm{b}, x}}{d_{\mathrm{b}, x}^{3}}}
$$

Gas-phase heat-transfer coefficients can be developed by analogy to their respective mass-transfer coefficients, replacing the diffusive term with an equivalent conductive term. This results in eqs 43 and 44 , where $k_{g, x}$ is the thermal conductivity of the gas.

$$
\begin{aligned}
H_{\mathrm{bc}, x}= & 1.32 \times 4.5\left(\frac{v_{\mathrm{mf}} \rho_{g, x} c_{p, g, x}}{d_{\mathrm{b}, x}}\right)+5.85 \\
& {\left[\frac{\left(k_{g, x} \rho_{g, x} c_{p, g, x}\right)^{0.5} g^{0.25}}{d_{\mathrm{b}, x}{ }^{5 / 4}}\right] }
\end{aligned}
$$

$$
H_{c e, x}=6.78 \sqrt{\frac{\varepsilon_{d, x} v_{b, x} k_{g, x} \rho_{g, x} c_{p, g, x}}{d_{b, x}^{3}}}
$$

For the solid phase, only mixing of solids between the cloudwake region and emulsion region needs to be considered, and Kunii and Levenspiel proposed that the interchange of solids could be expressed using eq $45,{ }^{2}$ based on the rate at which solids are swept into the cloud surrounding each bubble.

$$
K_{\mathrm{ce}, \mathrm{b} s, x}=\frac{3\left(1-\varepsilon_{\mathrm{d}, x}\right)}{\left(1-\delta_{x}\right) \varepsilon_{\mathrm{d}, x}}\left(\frac{v_{\mathrm{mf}}}{d_{\mathrm{b}, x}}\right)
$$

For gas-solid heat transfer in fluidized beds, Kothari ${ }^{27}$ developed an empirical correlation between the Nusselt and Reynolds numbers that fits a range of reported experimental data for heat-transfer coefficients. The correlation proposed by Kothari is shown in eq 46, where the Reynolds number should be calculated using the conditions in the emulsion region.

$$
N u_{p, x}=\frac{h_{p, x} d_{p}}{k_{g, x}}=0.03 R e_{\mathrm{d}, x}^{1.3}
$$

Heat Transfer to Immersed Heat-Exchanger Tubes. In systems involving highly exothermic and endothermic reactions, it is often necessary to use heat exchangers to provide or remove heat from the fluidized bed. Heat transfer between the bed and its surroundings can occur through the walls of the vessel, the distributor plate at the bottom of the bed, or through internal heat exchanger tubes immersed within the fluidized bed. For beds with large diameters and internal heat exchangers, the most significant of mode of heat transfer will be via the internal heat exchangers, and thus only these are considered in the current model. In order to predict the heat transfer to and from a set of immersed heat-exchanger tubes, the model of Mickley and Fairbanks ${ }^{18,28}$ was used, with the correlations of Baskakov et al. ${ }^{29}$ for vertical tubes. This model estimates the overall heat-transfer coefficient from the heat-exchanger tubes by predicting the individual contributions of contact between the heat exchangers and gas and solids, respectively. First, the thermal conductivity of an emulsion packet, $k_{p, a, x}$ is calculated using eq $47,{ }^{18}$

$$
k_{p, a, x}=\left(3.58-2.5 \varepsilon_{\mathrm{d}, x}\right) k_{g, x}\left(\frac{k_{p}}{k_{g, x}}\right)^{0.46\left(1-\varepsilon_{\mathrm{d}, x}\right)}
$$

where $k_{p}$ is the thermal conductivity of the solid particles.

Next, the residence time of emulsion packets at the heatexchanger surface $\left(\tau_{x}\right)$ is calculated using the correlation proposed by Baskakov et al. ${ }^{29}$ (eq 48).

$$
\tau_{x}=0.44\left[\frac{d_{p g}}{v_{\mathrm{mf}}^{2}\left(f_{n, x}-a_{\mathrm{h}}\right)^{2}}\right]^{0.14}\left(\frac{d_{p}}{d_{\mathrm{HX}}}\right)^{0.225}
$$

Here, $f_{n, x}=\left(v_{g, x} / v_{\mathrm{mf}}\right)$ is the fluidization number of the bed and $a_{h}$ $=0.8$ is an empirical constant. ${ }^{29} \mathrm{Next}$, the fraction of time that the heat exchanger surface is exposed to emulsion packets, $f_{\mathrm{b}, x}$ can be calculated using eq 49:

$$
f_{\mathrm{b}, x}=0.33\left[\frac{v_{\mathrm{mf}}^{2}\left(f_{n, x}-a_{\mathrm{h}}\right)^{2}}{d_{p} g}\right]^{0.14}
$$

Mickley and Fairbanks proposed that the heat-transfer coefficient between the heat exchanger tubes and the emulsion 
packets, $h_{\mathrm{d}, x}$, could be calculated using eq 50 (taken from Chen $^{18}$ ):

$$
h_{\mathrm{d}, x}=2 \sqrt{\frac{k_{p, a, x} \rho_{s} c_{p, s, \mathrm{e}, x}\left(1-\varepsilon_{\mathrm{d}, x}\right)}{\pi \tau_{x}}}
$$

Baskakov et al. proposed the following correlation for the tubebubble Nusselt number with the Archimedes and Prandtl numbers, ${ }^{29}$ which is shown as eq 51 :

$$
N u_{h, x}=\frac{h_{l, x} d_{p}}{k_{g, x}}=0.009 \mathrm{Ar}_{x}^{0.5} \operatorname{Pr}_{x}^{0.33}
$$

Finally, the overall heat-transfer coefficient between the heat exchanger tubes and the bed $\left(h_{\mathrm{t}, x}\right)$ can be calculated from the bubble and emulsion packet heat-transfer coefficients and the fraction of time each spend in contact with the heat exchanger tubes, as shown in eq 52 .

$$
h_{\mathrm{t}, x}=f_{\mathrm{b}, x} h_{\mathrm{d}, x}+\left(1-f_{\mathrm{b}, x}\right) h_{l, x}
$$

Pressure Drop and Additional Equations. A significant factor in the performance and operation of fluidized-bed reactors is the pressure drop that occurs across the bed. Because of the high solids volume fractions encountered within bubbling fluidized beds, the most significant factor contributing to the pressure drop is the weight of the solid bed, with all other pressure drop terms being negligible in comparison. This results in eq 53:

$$
\frac{\partial P_{x}}{\partial x}=-\left(1-\varepsilon_{x}\right) \rho_{s} g
$$

Since the bubble region is assumed to be free of solids and the cloud-wake and emulsion regions are assumed to have the same voidage fraction, the average voidage fraction within a slice $\left(\varepsilon_{x}\right)$ can be calculated by eq 54 :

$$
\left(1-\varepsilon_{x}\right)=\left(1-\varepsilon_{\mathrm{d}, x}\right)\left(1-\delta_{x}\right)
$$

Allowance should also be made for the pressure drop across the distributor plate at the bottom of the reactor. Having a sufficient pressure drop across the distributor plate is necessary to ensure good fluidization of the bed and to minimize channelling of the gas through part of the bed. As a rough guide, it has been suggested that the pressure drop across the distributor should be equal to $\sim 20 \%$ of the pressure drop across the bed. ${ }^{2}$ Including the pressure drop across the distributor plate gives the following equation for the pressure at the gas inlet to the reactor:

$$
P_{\text {inlet }}=P_{0}+\Delta P_{\text {distributor }}
$$

Reaction Kinetics. In addition, equations are required to describe the mass transfer and kinetics of the reactions between the gas and solids. These will vary depending on the specific process being conducted within the bed. Thus, a model for the rate of reaction(s) will need to be developed for each individual process. The equations used in this paper are written in terms of the rate of formation for each component per unit volume of solids; however, other forms of the reaction rate can be easily substituted.

In order to demonstrate and test the current model, a solid sorbent developed by NETL for the adsorption of $\mathrm{CO}_{2}$ (sorbent NETL 32D) was used as the test material. This sorbent consists of a mesoporous silica substrate into which a mixture of amines is impregnated. $\mathrm{CO}_{2}$ diffuses into the pores of the substrate, where it reacts with the impregnated amines to form carbamate. Water is also adsorbed into the substrate and can react with the amines and $\mathrm{CO}_{2}$ to form bicarbonate.

A simple lumped parameter kinetic and equilibrium model has been developed for this sorbent by Lee et al., ${ }^{30}$ which accounts for the adsorption of both $\mathrm{CO}_{2}$ and water by the sorbent. The model assumes that the adsorption of water and $\mathrm{CO}_{2}$ can be modeled as a system of three inter-related chemical reactions. $\mathrm{CO}_{2}$ is assumed to be adsorbed by two parallel reactions: one representing the reaction between the $\mathrm{CO}_{2}$ and amine to form carbamate and one representing the reaction between $\mathrm{CO}_{2}$ and amine in the presence of adsorbed water to form bicarbonate. Water vapor is assumed to undergo physical adsorption into the amines. This resulted in the following set of reactions (eqs 56, 57, and 58):

$$
\begin{aligned}
r_{\mathrm{H}_{2} \mathrm{O}}= & k_{1}\left[P y_{\mathrm{H}_{2} \mathrm{O}}-\left(\frac{1}{K_{1}}\right) n_{\mathrm{H}_{2} \mathrm{O}} \rho_{s}\right] \\
r_{\text {carb }}= & k_{2}\left[\left(1-\frac{2 n_{\text {carb }} \rho_{s}+n_{\text {bicarb }} \rho_{s}}{n_{v}}\right)\left(P y_{\mathrm{CO}}\right)^{m}\right. \\
& \left.-\left(\frac{1}{K_{2}}\right) n_{\text {carb }} \rho_{s}^{2}\left(\frac{n_{\text {carb }}+n_{\text {bicarb }}}{n_{v}}\right)\right] \\
r_{\text {bicarb }}= & k_{3}\left[\left(1-\frac{2 n_{\text {carb }} \rho_{s}+n_{\text {bicarb }} \rho_{s}}{n_{v}}\right) n_{\mathrm{H}_{2} \mathrm{O}} \rho_{s}\left(P y_{\mathrm{CO}}\right)\right. \\
& \left.-\left(\frac{1}{K_{3}}\right) n_{\text {bicarb }} \rho_{s}^{2}\left(\frac{n_{\text {carb }}+n_{\text {bicarb }}}{n_{v}}\right)\right]
\end{aligned}
$$

Equilibrium and rate constants were fitted to experimental data obtained by thermogravimetric analysis (TGA), using the forms shown in eqs 59 and 60.

$$
\begin{aligned}
& k_{i}=A_{i} T \exp \left(\frac{-E_{i}}{R T}\right) \\
& K_{i}=\exp \left(\frac{\Delta S_{i}}{R}\right) \exp \left(\frac{-\Delta H_{i}}{R T}\right) / P
\end{aligned}
$$

Each of the three chemical reactions was represented using a separate reaction term in the mass and energy balances, and the heat of reaction was taken to be equal to the fitted $\Delta H_{i}$. Since no data on the temperature dependence of the heat of reaction were available, it was assumed to be constant within the model. Equilibrium and kinetic parameters for eqs 56-57 are listed in Tables 1 and 2.

\section{MODEL IMPLEMENTATION}

The model discussed above was implemented in both Aspen Custom Modeler (ACM) (Aspen Technology, Inc.) and gPROMS (Process Systems Enterprise, Ltd.). While both $\mathrm{ACM}$ and gPROMS contain inbuilt partial-differential equation

Table 1. Equilibrium Parameters

$\begin{array}{ccc} & \Delta H_{i}(\mathrm{~J} / \mathrm{mol}) & \Delta H_{i}(\mathrm{~J} / \mathrm{mol} \mathrm{K}) \\ K_{\mathrm{a}} & -52100 & -78.5 \\ K_{\mathrm{b}} & -36300 & -88.1 \\ K_{\mathrm{c}} & -64700 & -174.6\end{array}$


Table 2. Kinetic Parameters

\begin{tabular}{ccc} 
& $E_{i}(\mathrm{~J} / \mathrm{mol})$ & $\log _{10} A_{i}$ \\
$k_{\mathrm{a}}$ & 28200 & 4.750 \\
$k_{\mathrm{b}}$ & 58200 & 0.418 \\
$k_{\mathrm{c}}$ & 57700 & 2.000 \\
& & \\
$m_{1}$ & 1.17 & \\
\hline
\end{tabular}

(PDE) solvers, a compartment-based approach, where the axial differential terms were expressed as finite differences, was used in implementing the model, since it was determined that this improved the reliability and robustness of the model. A firstorder backward difference method was used for all PDEs except for those involving the solid phase in the emulsion region, where a first-order forward finite difference method was used due to the reversed flow direction. Physical properties of the gas phase were calculated using commercial property packages (Aspen Properties in ACM and Multiflash in gPROMS) using cubic equations of state. Physical properties of the solids were taken from experimental measurements.

A set of conditions were chosen to establish a baseline for testing of the model, which are given in Table 3 and are shown in Figure 3. Solids were fed and removed at the top of the bed ( $x=$ $L_{\mathrm{b}}$, top feed and overflow outlet) and many single-pass heat exchanger tubes were present in the bed with a square-pitch arrangement. The gas leaving the bed (at $x=L_{\mathrm{b}}$ ) was specified to be at atmospheric pressure, and the pressure of the incoming gas was calculated by the model. A bundle of 2000 vertical heat exchanger tubes with a diameter of $0.03 \mathrm{~m}$ were modeled within the bed. The heat exchanger tubes were modeled as single pass tubes, with fresh fluid fed from above the bed and removed from the bottom. This setup is not really practical, because this requires passing the heat exchanger tubes through the distributor plate, which would result in severe erosion on the tubes near the distributor. However, this system is simpler to model and allows for easy verification of the model equations. Other types of heat exchangers could be used instead, and simulations have been conducted using more realistic U-tube-type heat exchangers; however, these will not be presented here. Properties of the solid sorbent (Geldart group A) are shown in Table 4.

First, a series of simulations was run in order to study the dependence of the simulation results on the number of compartments, or discretization points, used, The number of discretization points was varied between 10 and 205 discretization points, and Figure 4 shows the predicted removal of $\mathrm{CO}_{2}$ from a stream of flue, as a function of the number of discretization points used in the model. As can be seen, the prediction of the model vary significantly with few discretization points, but begins to converge as the number of discretization points increases. Based on the results of this study, it was decided that 100 discretization points represented a good compromise between

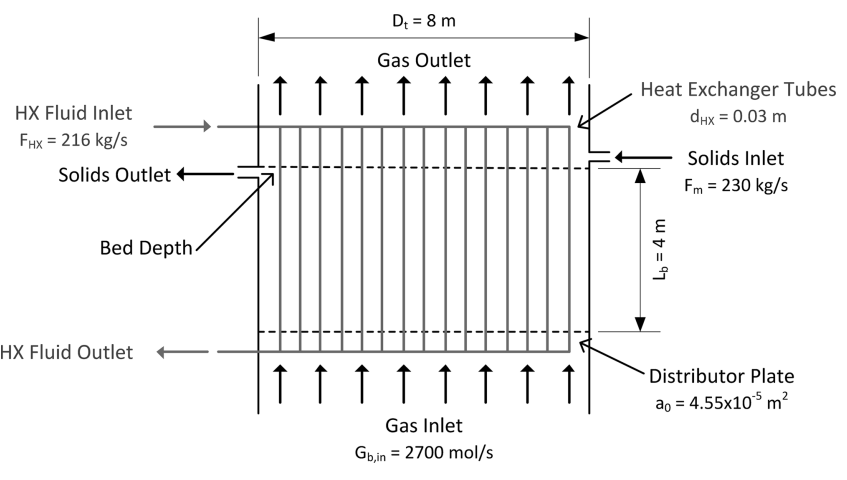

Figure 3. Schematic diagram of an example bed.

Table 4. Sorbent Properties

\begin{tabular}{ll} 
parameter & \multicolumn{1}{c}{ value } \\
$c_{p, \text { sorb }}$ & $1.13 \mathrm{~J} /(\mathrm{kg} \mathrm{K})$ \\
$d_{p}$ & $150 \mu \mathrm{m}$ \\
$\varepsilon_{\mathrm{mf}}$ & 0.5 \\
$F$ & 0 \\
$k_{p}$ & $1.36 \mathrm{~J} /(\mathrm{m} \mathrm{K} \mathrm{s})$ \\
$\phi_{s}$ & 1 \\
$\rho_{s}$ & $442 \mathrm{~kg} / \mathrm{m}^{3}$
\end{tabular}

accuracy and complexity (and, hence, solution time) for the model.

Using the model to simulate the conditions shown in Tables 3 and 4 clearly shows the axial variations that can occur within fluidized beds. Figure 5 shows the carbon capture as a function of height above the distributor plate, while Figure 6 shows the $\mathrm{CO}_{2}$ loading on the solid sorbent as a function of height above the distributor. It can be seen that the carbon capture fraction varies across the bed, as is expected; however, the loading of the solid sorbent remains relatively constant. This demonstrates the significant amount of mixing that occurs within the fluidized bed. It can be seen that most of the removal of carbon dioxide occurs in the region immediately above the distributor plate, where the driving force is most significant and begins to tail off rapidly as the height increases. This indicates that there is a limit to the amount of removal that can be obtained within a single bed and that multiple shallow beds in series may be more efficient than a single large bed. This behavior is similar to that of other reactor types, which show well-mixed behavior.

Figure 7 shows the flow rate of gas through the fluidized bed, as a function of bed depth. It can be seen that there is significant variation in the flow rate of gas across the bed, because of the adsorption of species from the gas. As previously mentioned, for the conditions simulated, it can be seen that the reaction is most rapid in the lower regions of the bed, while, in the upper regions of the bed, the flow rate seems to be approaching a stable value,

Table 3. Base Case Conditions

\begin{tabular}{|c|c|c|c|c|c|c|c|}
\hline \multicolumn{2}{|r|}{ Geometry } & \multicolumn{2}{|c|}{ Gas Conditions } & \multicolumn{2}{|c|}{ Solid Conditions } & \multicolumn{2}{|c|}{ HX Fluid Conditions } \\
\hline parameter & value & parameter & value & parameter & value & parameter & value \\
\hline$D_{\mathrm{t}}$ & $8 \mathrm{~m}$ & $G_{\mathrm{b}, \text { in }}$ & $2700 \mathrm{~mol} / \mathrm{s}$ & $F_{\text {sorb,in }}$ & $230 \mathrm{~kg} / \mathrm{s}$ & $F_{\mathrm{HX}, \mathrm{in}}$ & $216 \mathrm{~kg} / \mathrm{s}$ \\
\hline$L_{\mathrm{b}}$ & $4 \mathrm{~m}$ & $T_{g, \text { in }}$ & $313.15 \mathrm{~K}$ & $T_{\text {sorb,in }}$ & $363.15 \mathrm{~K}$ & $P_{\mathrm{HX}, \mathrm{in}}$ & $101325 \mathrm{~Pa}$ \\
\hline$d_{\mathrm{HX}}$ & $0.03 \mathrm{~m}$ & $y_{\mathrm{g}, \mathrm{CO}_{2}, \text { in }}$ & 0.12 & $n_{\mathrm{HCO}_{3}, \mathrm{in}}$ & $81.77 \mathrm{~mol} / \mathrm{m}^{3}$ & $T_{\mathrm{HX}, \mathrm{in}}$ & $305.65 \mathrm{~K}$ \\
\hline$N_{\mathrm{HX}}$ & 2000 & $y_{\mathrm{g}, \mathrm{H}_{2} \mathrm{O}, \text { in }}$ & 0.12 & $n_{\mathrm{H}_{2} \mathrm{O}, \text { in }}$ & $163.54 \mathrm{~mol} / \mathrm{m}^{3}$ & & \\
\hline$a_{0}$ & $4.55 \times 10^{-5} \mathrm{~m}^{2}$ per orifice & $y_{\mathrm{g}, \mathrm{N}_{2} \text { in }}$ & 0.76 & $n_{\mathrm{NHCO}_{2} \text { in }}$ & $572.39 \mathrm{~mol} / \mathrm{m}^{3}$ & $P_{\mathrm{Lb}}$ & $101325 \mathrm{~Pa}$ \\
\hline
\end{tabular}




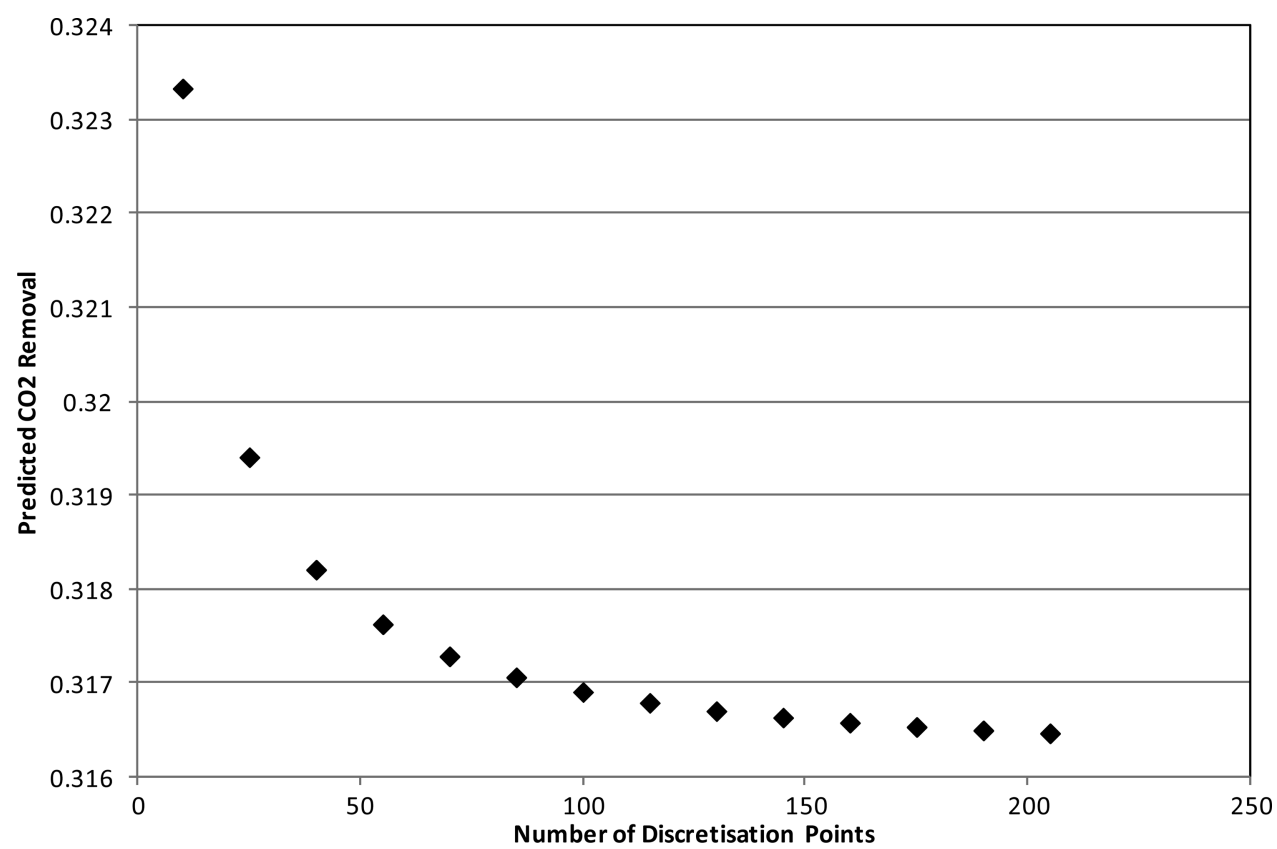

Figure 4. Dependence of predicted $\mathrm{CO}_{2}$ removal on the number of discretization points.

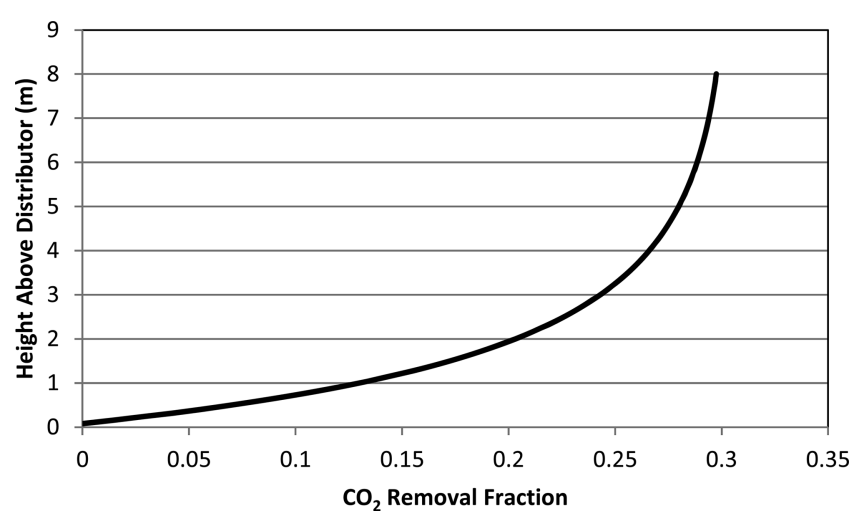

Figure 5. $\mathrm{CO}_{2}$ removal fraction, as a function of height above the distributor.

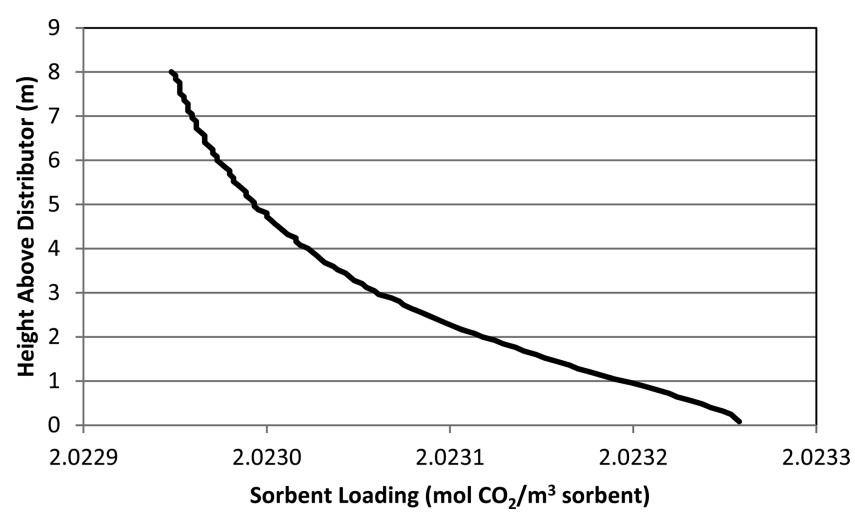

Figure 6. Sorbent loading, as a function of height above the distributor.

indicating an approach to equilibrium. These changes in the gas flow rate contribute to changes in the superficial gas velocity as a function of bed depth, as shown in Figure 8. Here, it can be seen that, in the lower regions of the bed, the superficial gas velocity initially decreases, because of the rapid adsorption of gas decreasing the flow rate; however, above a point $\sim 1 \mathrm{~m}$ above the

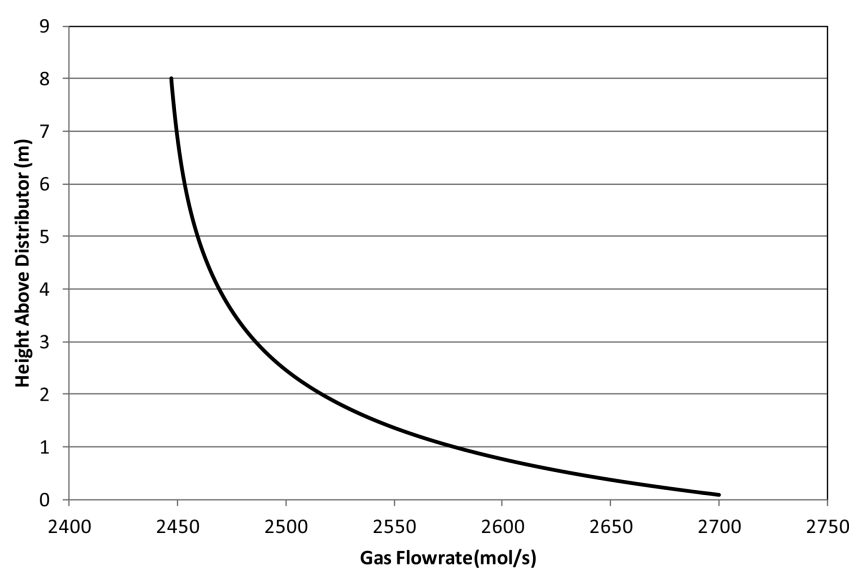

Figure 7. Axial profile of the gas flow rate.

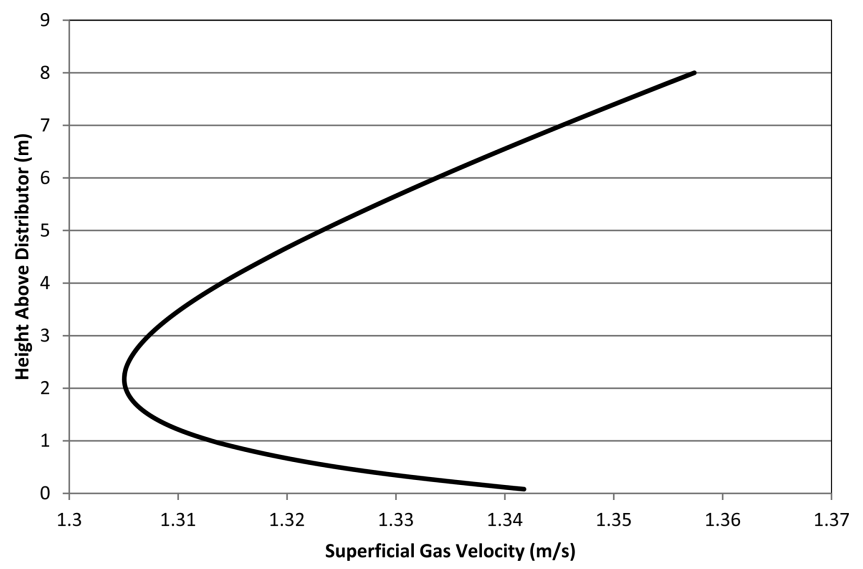

Figure 8. Axial profile of the superficial gas velocity.

distributor, the superficial gas velocity begins to increase as expansion of the gas (due to decreasing pressure) begins to dominate the reduction in flow rate due to adsorption. 
In developing their model for bubbling fluidized beds, Kunii and Levenspiel ${ }^{2,12}$ assumed that an average bubble diameter could be used to describe the hydrodynamics of the bubbling bed. Figure 9 shows the predicted bubble diameter as a function

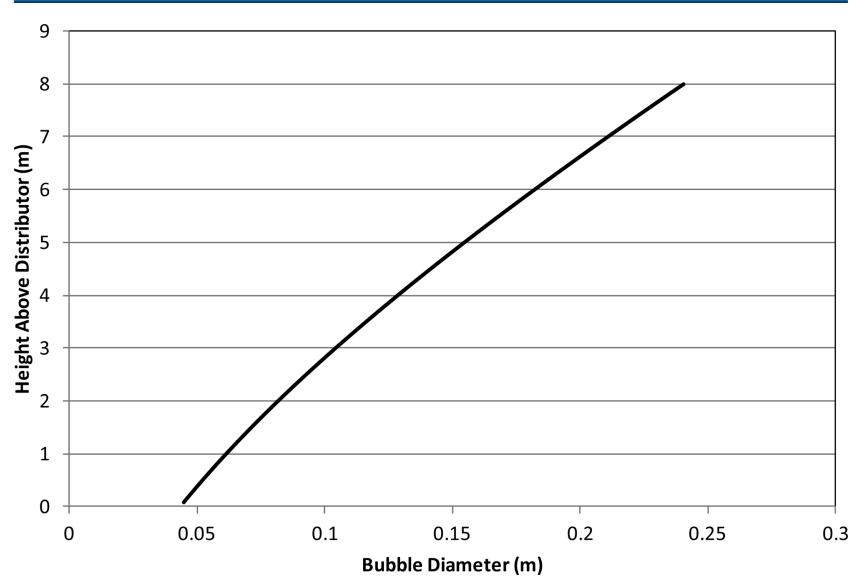

Figure 9. Bubble diameter, as a function of height above the distributor.

of height above the distributor from the model. From Figure 9, it can be seen that there is significant variation in bubble diameter across the bed, with bubbles growing to a size at the top of the bed $\sim 5$ times their initial diameter. It can also be seen that, for this case, the bubbles do not reach an upper size limit, either due to equilibrium between splitting and coalescence or due to restriction by the hydraulic diameter. For Geldart group A materials, such as the one simulated in these studies, it is often assumed that the bubbles will rapidly reach an equilibrium diameter not far above the distributor. ${ }^{2}$ However, the equilibrium bubble diameter $\left(d_{\mathrm{be}}\right)$ predicted by the model for these conditions is $0.97-1.00 \mathrm{~m}$; thus, the bubble diameters are not approaching the equilibrium size limit.

As the bubbles grow within the bed, the wakes associated with them also grow, resulting in more solids being carried up the bed behind each bubble. Combined with the acceleration of the bubbles as they rise, this results in a significant variation in the upward flux of solids in the bed due to the rising bubbles (and, consequently, the opposing downward flux in the emulsion region). This can be seen in Figure 10, which shows the superficial upward flux of solids in the bubble wakes as a function of height above the distributor. This variation in the axial flux of

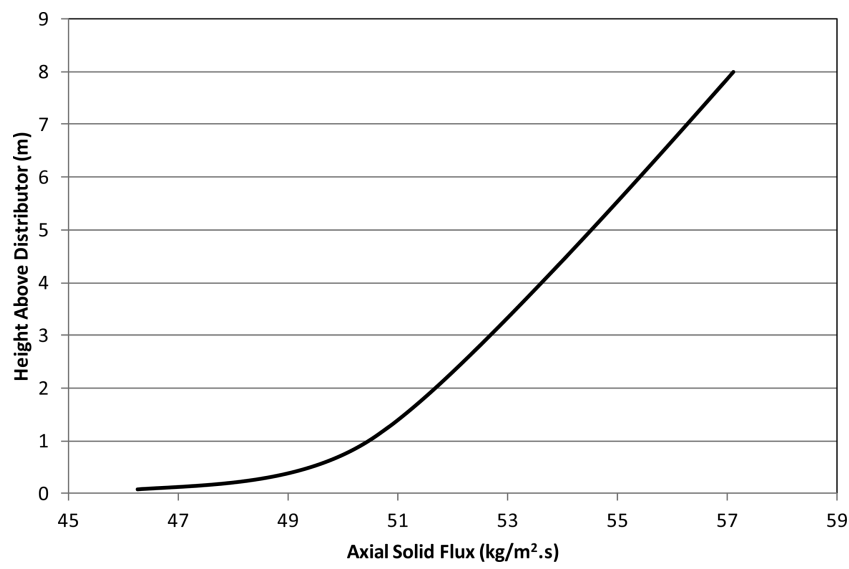

Figure 10. Upward flux of solids in bubble wakes, as a function of height above the distributor. solid results in different levels of solids mixing in the axial direction, with better mixing of solids occurring in the lower regions of the bed where the axial flux is lower. Thus, mixing between the cloud-wake and emulsion regions is more significant, in comparison to the axial flows.

The rate of adsorption and final equilibrium of gas species is strongly dependent on the temperature of the solids within the bed. The temperature of the solids is, in turn, affected by the heat released as the gaseous species adsorb onto the solids. Figure 11

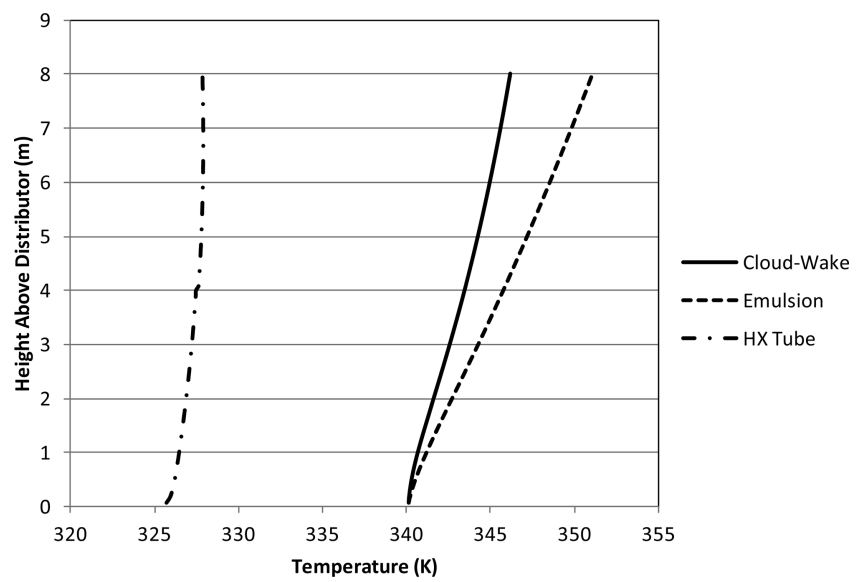

Figure 11. Solid phase temperatures, as a function of height above the distributor.

shows the predicted temperature of the solids in both the cloudwake and emulsion regions of the model, as well as the predicted temperature of the heat exchanger tubes in contact with the bed. It can be seen that the temperature of the solids is very uniform across the entire bed, suggesting very good mixing of the solids. In the emulsion region, it can be seen that the temperature at the top of the bed is slightly higher than that in the middle regions of the bed, which is probably due to the introduction of hot solids at the top of the bed. The temperature of the solids also appears to increase toward the bottom of the bed, which is probably due to the heat released by the rapid adsorption reactions in the bottom of the bed. The cloud-wake region temperature appears to be fairly uniform across the entire bed, and the temperature difference between the two regions remains small.

In contrast, the gas-phase temperatures are less uniform, as can be seen in Figure 12. In the bubble region, it can be seen that the gas temperature varies significantly across the depth of the bed and that there is a significant temperature difference between the bubble and cloud-wake region. This indicates that the mixing between the two regions is relatively poor and that much of the gas is passing through the bed in the bubbles without contacting the solids. This is not unexpected, because of the relatively high gas velocity used in these simulations $(\sim 160$ times the minimum fluidization velocity) and agrees well with the observations of other researchers. ${ }^{2}$ The temperature of the gas in the emulsion region seems to be very similar to that of the solids in the emulsion region, which is to be expected, because of the good contact between gas and solids in this region, while the cloudwake region is intermediate to the other regions.

In order to study the behavior of the system and verify the model, a sensitivity study was performed to observe the response of the model to changes in some key input parameters. Some of the results of this study are shown in Figures 13-15. Some of the input parameters studied were the hydraulic diameter of the 


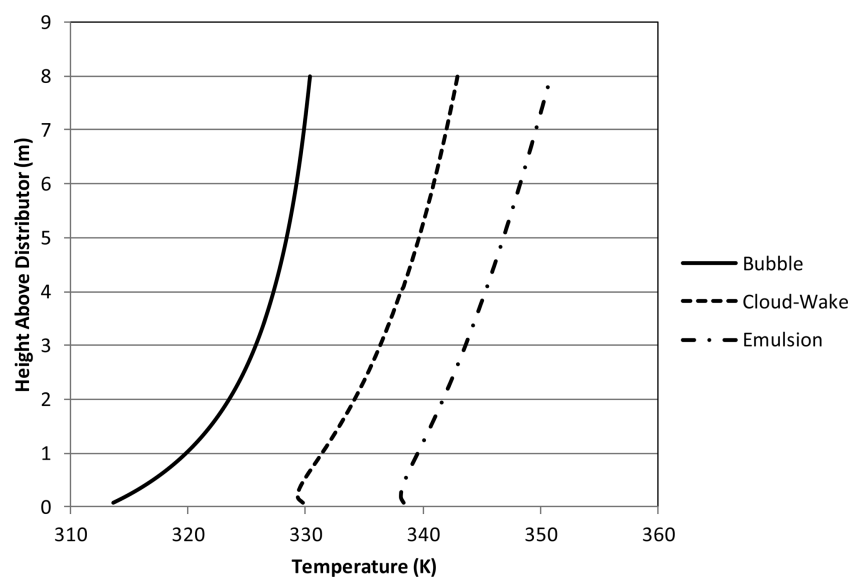

Figure 12. Gas-phase temperatures, as a function of height above the distributor.

system, which includes the effects of bed diameter and the size and spacing of the internal heat exchangers, the depth of the fluidized bed, the initial gas velocity above the distributor and the diameter and minimum fluidization voidage of the solid particles.

Figure 13 shows the effects of varying these variables between $80 \%$ and $120 \%$ of their base case values on the predicted removal

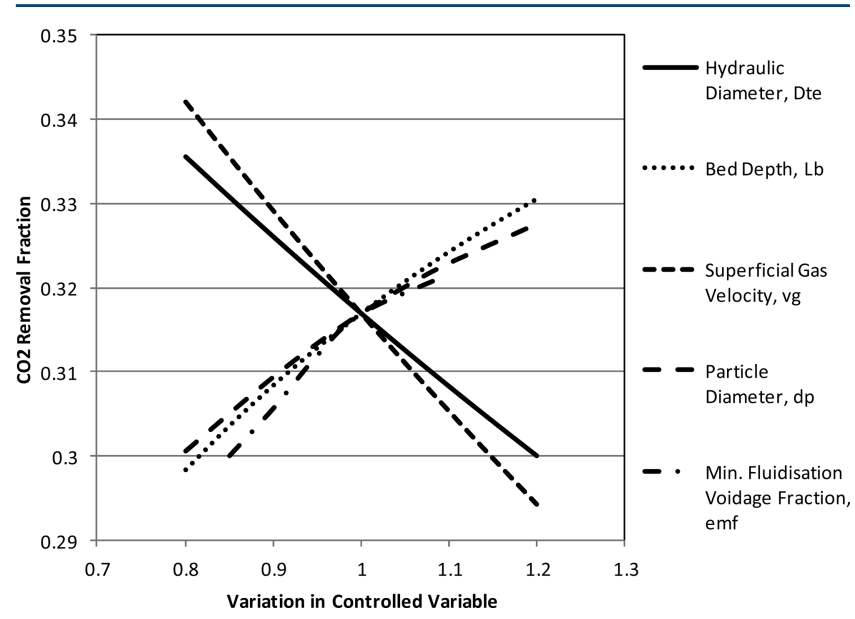

Figure 13. Sensitivity of $\mathrm{CO}_{2}$ removal fraction to key input variables.

of $\mathrm{CO}_{2}$ from the simulated gas. As can be seen, increasing the bed depth increases the removal of $\mathrm{CO}_{2}$, as is to be expected, because of the extra residence time of gas and sorbent, while increasing the gas velocity has the opposite effect. Increasing the particle diameter and minimum fluidization voidage fraction also improve $\mathrm{CO}_{2}$ removal due to better contacting between gas and solids in the emulsion and cloud-wake regions.

Figure 14 shows the response of the average bed voidage (an indicator of the overall hydrodynamics of the bed) to the same input variables. As can be seen, the variable with the most significant effect on the average bed voidage is the minimum fluidization voidage of the particles. This is because the minimum fluidization voidage has a strong effect on predicted voidage in the emulsion and cloud-wake regions, and thus the overall average voidage. Increasing the gas velocity also increases the average voidage of the bed due to the additional volume of bubbles that are formed. However, increasing the bed depth decreases the average voidage in the bed, which is due to the higher inlet gas pressure required at the distributor plate. This, in

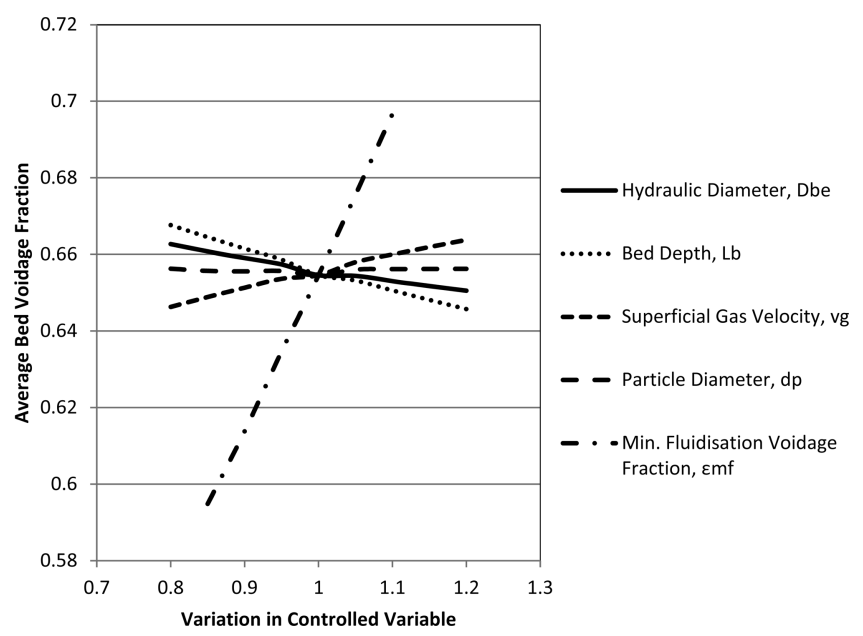

Figure 14. Sensitivity of average bed voidage fraction to key input variables.

turn, results in a denser gas flow in the lower regions of the bed, which results in a lower voidage.

Figure 15 shows the effects of varying the flue gas flow rate, temperature, and inlet $\mathrm{CO}_{2}$ concentration between $80 \%$ and

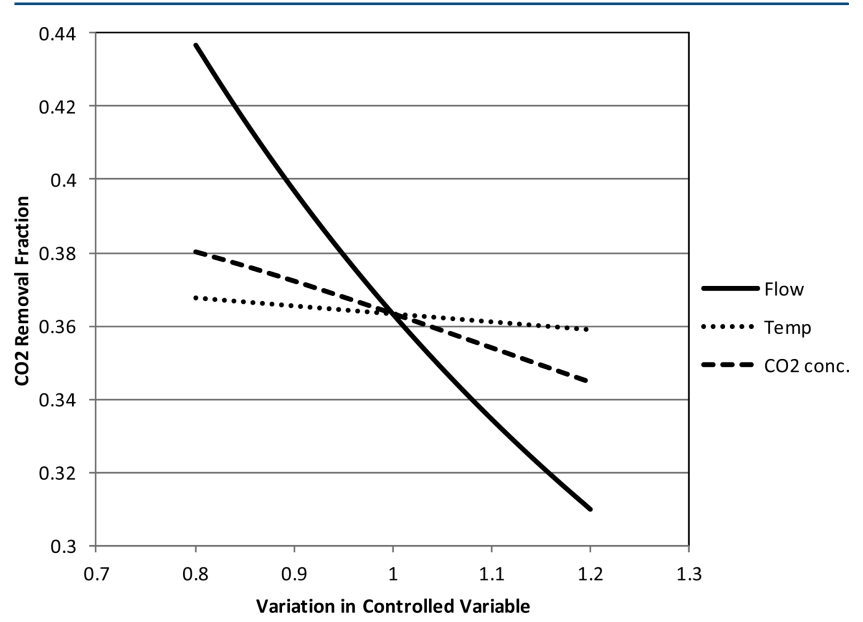

Figure 15. Sensitivity of $\mathrm{CO}_{2}$ removal fraction to flue gas variations.

$120 \%$ of their base case values on the predicted removal of $\mathrm{CO}_{2}$ from the simulated gas. As can be seen, decreasing the flow rate increases the fraction of $\mathrm{CO}_{2}$ removed, as is to be expected due to the increased residence time and decreased mass flow of $\mathrm{CO}_{2}$. However, a practical limit results from the need to maintain a minimum velocity for fluidization. Decreasing the temperature of the entering flue gas also increases the fraction of $\mathrm{CO}_{2}$ removed by increasing the working capacity of the sorbent. Finally, increased $\mathrm{CO}_{2}$ concentration in the flue gas actually decreases the fraction of $\mathrm{CO}_{2}$ adsorbed. Although the $\mathrm{CO}_{2}$ loading on the sorbent increases, and, thus, the total amount of $\mathrm{CO}_{2}$ adsorbed, the mixing that occurs in the bubbling bed limits the overall driving force that can be obtained as the flue gas exits the bed. As noted previously, this limits the amount of removal that can be obtained within a single bed, even when the $\mathrm{CO}_{2}$ concentration in the entering gas is at a higher concentration, because of the well-mixed behavior of the majority of the bed. These results would likely be different in a counter-currently staged contacting scheme. 


\section{DISCUSSION}

The one-dimensional (1-D), three-region model developed in this paper provides predictive capability while remaining computationally fast and flexible, and it can be easily adapted to any system of reactions. These features are important for process synthesis and optimization activities, where there is a need to perform a large number of simulations across a wide range of operating conditions without being able to conduct experiments to tune model parameters. As a 1-D model, however, the current model neglects any variations that may occur in the lateral direction. Lateral variations may arise due to the location of solid feed and discharge points, maldistribution of gas through the distributor, and channelling of gas and solid flow through the bed. In situations where these effects may be significant, a more complex two-dimensional (2-D) or threedimensional (3-D) approach may be needed to model the behavior of the bed accurately.

For the assumptions made in developing this model to be applicable, the superficial gas velocity should lie between $\sim 10 v_{\mathrm{mf}}$ and $v_{\text {tr }}$, i.e., within the bubbling and turbulent fluidization regimes. ${ }^{2,13}$ However, the model does not currently consider slugging behavior, which may occur for some materials, and care should be taken when applying this model to materials that may display slugging behavior. Also, many of the correlations used in this model have not been tested on large-scale fluidized beds, because of the difficulty in obtaining experimental data from these units, and the current model has yet to be validated against experimental results. Currently, work is being performed as part of CCSI to develop computational fluid dynamic simulations of large fluidized-bed reactors, which will be used to test, improve, and validate the current model.

The current model does not consider the behavior of the freeboard above the fluidized bed, which may have a significant effect on the performance of the reactor. As the superficial gas velocity is increased, the number of particles ejected into the freeboard of the vessel and possibly entrained with the gas will increase. These particles interact with the gas in the freeboard and additional reactions may occur. For beds operating at low gas velocities where entrainment and ejection of particles from the fluidized bed is small, it may be acceptable to neglect these effects. However, for beds operating at high gas velocities such as within the turbulent fluidization regime, it is likely that these effects cannot be neglected. A significant amount of work has been done on modeling the entrainment and ejection of particles from fluidized beds, and many models for this phenomena have been proposed (for example, see the work of Wen and Chen ${ }^{31}$ ). It is planned to include a model for these phenomena in future versions of this model. The current model also does not consider particle size distributions and attrition of particles; however, Kunii and Levenspiel suggest that the behavior of a fluidized bed can be accurately represented using the mean surface area to represent the particle size. ${ }^{2}$

\section{CONCLUSIONS}

This paper presents the development of a general 1-D, threeregion model for a bubbling fluidized bed adsorber, which accounts for the hydrodynamic behavior of the system. Demonstration of the model for a carbon capture application shows that a number of factors can affect the performance of a bubbling fluidized-bed adsorber. One of the most important factors relates to the well-mixed characteristics of the bed, which limits the driving force between the flue gas and the sorbent. This indicates the importance of considering counter currently staged bubbling fluidized bed configurations to attain the higher capture fractions necessary to significantly reduce $\mathrm{CO}_{2}$ emissions.

Although increased bed depth can also increase $\mathrm{CO}_{2}$ removal, increased bed depth negatively affects average voidage fraction within the bed, which is an even more important factor for attaining a high $\mathrm{CO}_{2}$ removal fraction. The higher bed depth causes an increased pressure drop across the bed, which increases the pressure at the bottom of the bed, reducing the average voidage. This increased pressure drop will also increase energy requirements for the blowers to move the flue gas.

Although this model has been demonstrated within the context of a carbon capture application, it is generally applicable for simulating any reacting bubbling fluidized-bed system. Results from the model are consistent with experimental data reported in the literature. Work is ongoing to rigorously validate the model for carbon capture applications through a combination of experiments and detailed computational fluid dynamics (CFD) simulations.

\section{AUTHOR INFORMATION}

\section{Corresponding Author}

*E-mail: David.Miller@NETL.DOE.GOV.

\section{Notes}

This article was prepared as an account of work sponsored by an agency of the United States Government. Neither the United States Government nor any agency thereof, nor any of their employees, makes any warranty, express or implied, or assumes any legal liability or responsibility for the accuracy, completeness, or usefulness of any information, apparatus, product, or process disclosed, or represents that its use would not infringe privately owned rights. Reference herein to any specific commercial product, process, or service by trade name, trademark, manufacturer, or otherwise does not necessarily constitute or imply its endorsement, recommendation, or favoring by the United States Government or any agency thereof. The views and opinions of authors expressed herein do not necessarily state or reflect those of the United States Government or any agency thereof.

The authors declare no competing financial interest.

\section{ACKNOWLEDGMENTS}

This research was supported in part by an appointment to the U.S. Department of Energy (DOE) Postgraduate Research Program at the National Energy Technology Laboratory administered by the Oak Ridge Institution for Science and Education. The authors gratefully acknowledge the assistance of J. Morinelly with updating the figures.

\section{NOMENCLATURE}

$a_{\mathrm{h}}=$ empirical constant

$a_{0}=$ area of distributor plate per orifice $\left(\mathrm{m}^{2}\right)$

$a_{\mathrm{p}}=$ specific surface area of solid particle $\left(\mathrm{m}^{2} / \mathrm{kg}\right)$

$\mathrm{Ar}=$ particle Archimedes number

$A_{\mathrm{X}}=$ cross-sectional area of fluidized bed $\left(\mathrm{m}^{2}\right)$

$C=$ gas phase concentration $\left(\mathrm{mol} / \mathrm{m}^{3}\right)$

$c_{\mathrm{p}}=$ heat capacity $(\mathrm{J} /(\mathrm{mol} \mathrm{K}))$

$c_{\mathrm{p}, \mathrm{s}}=$ heat capacity of unloaded sorbent $(\mathrm{J} /(\mathrm{kg} \mathrm{K}))$

$C_{\mathrm{r}}=$ empirical coefficient

$d_{\mathrm{b}}=$ diameter of a single bubble $(\mathrm{m})$

$d_{\mathrm{b}, \mathrm{e}}=$ equilibrium diameter of bubbles $(\mathrm{m})$

$d_{\mathrm{b}, \mathrm{m}}=$ maximum size of bubbles due to coalescence $(\mathrm{m})$ 
$d_{\mathrm{b}, \mathrm{u}}=$ unconstrained bubble diameter $(\mathrm{m})$

$d_{\mathrm{b}, 0}=$ initial diameter of a bubble at the distributor plate $(\mathrm{m})$

$d_{\mathrm{HX}}=$ diameter of heat exchanger tubes $(\mathrm{m})$

$D=$ diffusivity of species in bulk gas $\left(\mathrm{m}^{2} / \mathrm{s}\right)$

$d_{\mathrm{p}}=$ particle diameter $(\mathrm{m})$

$D_{\mathrm{t}}=$ diameter of reactor vessel $(\mathrm{m})$

$D_{\mathrm{t}, \mathrm{h}}=$ hydraulic diameter of fluidized bed $(\mathrm{m})$

$F=$ fraction of fine particles $(<45 \mu \mathrm{m})$

$f_{\mathrm{b}}=$ fraction of time heat exchanger surface is exposed to bubbles

$f_{\mathrm{c}}=$ cloud to bubble volume ratio $\left(\mathrm{m}^{3} / \mathrm{m}^{3}\right)$

$f_{\mathrm{n}}=$ fluidization number

$f_{\mathrm{w}}=$ wake to bubble volume ratio $\left(\mathrm{m}^{3} / \mathrm{m}^{3}\right)$

$F_{\text {sorb }}=$ flow rate of solids $(\mathrm{kg} / \mathrm{s})$

$g=$ acceleration due to gravity; $g=9.81 \mathrm{~m} / \mathrm{s}^{2}$

$G_{\mathrm{b}}=$ bubble region gas axial flow rate $(\mathrm{mol} / \mathrm{s})$

$h_{\mathrm{ads}}=$ specific enthalpy of adsorbed species $(\mathrm{J} / \mathrm{kg}$ sorbent $)$

$H_{\mathrm{bc}}=$ bubble to cloud-wake region gas phase heat transfer coefficient $\left(\mathrm{W} /\left(\mathrm{m}^{3} \mathrm{~K}\right)\right)$

$H_{\text {ce }}=$ cloud-wake to emulsion region gas phase heat transfer coefficient $\left(\mathrm{W} /\left(\mathrm{m}^{3} \mathrm{~K}\right)\right)$

$h_{\mathrm{d}}=$ heat-transfer coefficient between heat exchanger and emulsion packet $\left(\mathrm{J} /\left(\mathrm{m}^{2} \mathrm{~K} \mathrm{~s}\right)\right)$

$H_{g, \text { bulk }}=$ rate of heat transfer between bubble and emulsion regions due to bulk flow of gas $(\mathrm{W} / \mathrm{m})$

$h_{l}=$ heat-transfer coefficient between heat exchanger and bubble $\left(\mathrm{J} /\left(\mathrm{m}^{2} \mathrm{~K} \mathrm{~s}\right)\right)$

$h_{p}=$ gas-solids heat transfer coefficient $\left(\mathrm{J} / \mathrm{m}^{2} \mathrm{~K} \mathrm{~s}\right)$

$H_{s, \text { bulk }}=$ rate of heat transfer between cloud-wake and emulsion regions due to bulk flow of solids $(\mathrm{W} / \mathrm{m})$

$h_{\text {sorb }}=$ specific enthalpy of unloaded solid ( $/ \mathrm{kg}$ sorbent)

$h_{\text {sorb+ads }}=$ specific enthalpy of sorbent and adsorbed species $(\mathrm{J} /$ $\mathrm{kg}$ sorbent)

$h_{t}=$ heat exchanger heat transfer coefficient $\left(\mathrm{J} /\left(\mathrm{m}^{2} \mathrm{~K} \mathrm{~s}\right)\right)$

$\Delta H_{\mathrm{rxn}}=$ specific heat of reaction $(\mathrm{J} / \mathrm{mol})$

$J=$ superficial solids flux $\left(\mathrm{kg} /\left(\mathrm{m}^{2} \mathrm{~s}\right)\right)$

$K_{\mathrm{bc}}=$ bubble to cloud-wake region gas-phase mass-transfer coefficient $\left(\mathrm{s}^{-1}\right)$

$K_{\text {ce }}=$ cloud-wake to emulsion region gas-phase mass-transfer coefficient $\left(\mathrm{s}^{-1}\right)$

$K_{\text {ce,bs }}=$ cloud-wake to emulsion region solid-phase masstransfer coefficient $\left(\mathrm{m}^{3}\right.$ solid $/\left(\mathrm{m}^{3}\right.$ bubbles $\left.\left.\mathrm{s}\right)\right)$

$K_{\mathrm{d}}=$ bubble to emulsion region gas-phase bulk flow coefficient $\left(\mathrm{m}^{2} / \mathrm{s}\right)$

$k_{g}=$ thermal conductivity of gas $(\mathrm{J} /(\mathrm{m} \mathrm{K} \mathrm{s}))$

$K_{g, \text { bulk }}=$ rate of gas phase bulk flow between bubble and emulsion regions $(\mathrm{mol} /(\mathrm{m} \mathrm{s}))$

$k_{\mathrm{p}}=$ thermal conductivity of solid particles $(\mathrm{J} /(\mathrm{m} \mathrm{K} \mathrm{s}))$

$k_{\mathrm{p}, \mathrm{a}}=$ thermal conductivity of emulsion packet $(\mathrm{J} /(\mathrm{m} \mathrm{K} \mathrm{s}))$

$K_{s, \text { bulk }}=$ rate of solid phase bulk flow between cloud-wake and emulsion regions $(\mathrm{mol} /(\mathrm{m} \mathrm{s}))$

$L_{\mathrm{b}}=$ depth of fluidized bed $(\mathrm{m})$

$n=$ concentration of adsorbed species in sorbent $(\mathrm{mol} / \mathrm{kg}$ sorbent)

$N_{\mathrm{HX}}=$ number of heat exchanger tubes

$N u_{\mathrm{h}}=$ heat exchanger Nusselt number

$N u_{\mathrm{p}}=$ particle Nusselt number

$P=$ gas pressure $(\mathrm{Pa})$

$\mathrm{Pr}=$ Prandlt number

$r=$ rate of reaction $\left(\mathrm{mol} /\left(\mathrm{m}^{3} \mathrm{~s}\right)\right)$

$R e_{\mathrm{d}}=$ emulsion region Reynolds number

$R e_{\mathrm{p}, \mathrm{mf}}=$ particle Reynolds number at minimum fluidization conditions
$T=$ temperature $(\mathrm{K})$

$\Delta T_{\mathrm{HX}}=$ temperature difference between heat exchanger tubes and emulsion region $(\mathrm{K})$

$T_{\text {ref }}=$ thermodynamic reference temperature $(\mathrm{K})$

$u_{s}=$ emulsion region solids velocity $(\mathrm{m} / \mathrm{s})$

$v_{\mathrm{b}}=$ axial bubble velocity $(\mathrm{m} / \mathrm{s})$

$v_{\mathrm{e}}=$ gas velocity in emulsion region $(\mathrm{m} / \mathrm{s})$

$v_{g}=$ superficial gas velocity $(\mathrm{m} / \mathrm{s})$

$v_{\mathrm{mf}}=$ minimum fluidization velocity $(\mathrm{m} / \mathrm{s})$

$x=$ height above distributor plate $(\mathrm{m})$

$y=$ gas phase mole fraction $(\mathrm{mol} / \mathrm{mol})$

\section{Greek Characters}

$\alpha=$ cloud-wake to bubble volume ratio $\left(\mathrm{m}^{3} / \mathrm{m}^{3}\right)$

$\gamma_{1}, \gamma_{2}, \gamma_{3}=$ bubble growth coefficients

$\delta=$ bubble volume fraction

$\varepsilon=$ cross-sectional average voidage $\left(\mathrm{m}^{3} / \mathrm{m}^{3}\right)$

$\varepsilon_{\mathrm{d}}=$ emulsion region voidage $\left(\mathrm{m}^{3} / \mathrm{m}^{3}\right)$

$\varepsilon_{\mathrm{mf}}=$ voidage at minimum fluidization conditions $\left(\mathrm{m}^{3} / \mathrm{m}^{3}\right)$

$\mu_{g}=$ dynamic viscosity of gas $(\mathrm{kg} /(\mathrm{m} \mathrm{s}))$

$\rho_{g}=$ gas density $\left(\mathrm{kg} / \mathrm{m}^{3}\right)$

$\rho_{s}=$ solid density $\left(\mathrm{kg} / \mathrm{m}^{3}\right)$

$\tau=$ bubble residence time at heat exchanger surface (s)

$\phi_{\mathrm{s}}=$ particle sphericity

\section{Subscripts}

$\mathrm{b}=$ bubble region

$\mathrm{c}=$ cloud-wake region

$\mathrm{e}=$ emulsion region

$g=$ gas phase

$i=$ adsorbed species

$j=$ gaseous species

$k=$ reaction

$r=$ region

$s=$ solid phase

$\mathrm{t}=$ total

$x=$ value at height $x$

\section{REFERENCES}

(1) Abrahamsen, A. R.; Geldart, D. Behaviour of Gas-Fluidized Beds of Fine Powders. Part II. Voidage of Dense Phase in Bubbling Beds. Powder Technol. 1980, 26, 47-55.

(2) Kunii, D.; Levenspiel, O. Fluidization Engineering, 2nd Edition; Butterworth-Heinemann: Boston, 1991.

(3) Bi, H. T.; Ellis, N.; Abba, I. A.; Grace, J. R. A State-of-the-Art Review of Gas-Solid Turbulent Fluidization. Chem. Eng. Sci. 2000, 55, $4789-4825$

(4) Smoulders, K.; Baeyens, J. Gas Fluidized Beds Operating at High Velocities: A Critcial Review of Occuring Regimes. Powder Technol. 2001, 119, 269-291.

(5) Horio, M.; Nonaka, A.; Sawa, Y.; Muchi, I.; New, A. Similarity Rule for Fluidized Bed Scale-Up. AIChE J. 1986, 32 (9), 1466-1482.

(6) Glicksman, L.; Hyre, M.; Woloshun, K. Simplified Scaling Relationships for Fluidized Beds. Powder Technol. 1993, 77, 177-199.

(7) Nicastro, M. T.; Glicksman, L. R. Experimental Verification of Scaling Relationships for Fluidized Bed. Chem. Eng. Sci. 1984, 39 (9), 1381-1391.

(8) de Souza-Santos, M. L. Comprehensive Modelling and Simulation of Fluidized Bed Boilers and Gasifiers. Fuel 1989, 68, 1507-1521.

(9) Davidson, J. F.; Harrison, D. Fluidized Particles. Cambridge University Press: New York, 1963.

(10) Kato, K.; Wen, C. Y. Bubble Assemblage Model for Fluidized Bed Catalytic Reactors. Chem. Eng. Sci. 1969, 24, 1351-1369.

(11) Kunii, D.; Levenspiel, O. Bubbling Bed Model: Model for the Flow of Gas through a Fluidized Bed. Ind. Eng. Chem. Fundam. 1968, 7 (3), 446-452. 
(12) Kunii, D.; Levenspiel, O. Fluidized Reactor Models. 1. For Bubbling Beds of Fine, Intermediate and Large Particles. 2. For the Lean Phase: Freeboard and Fast Fluidization. Ind. Eng. Chem. Res. 1990, 29 (7), 1226-1234.

(13) de Souza-Santos, M. L.; New, A. Version of CSFB, Comprehensive Simulator for Fluidised Bed Equipment. Fuel 2007, $86,1684-1709$.

(14) Geldart, D.; Abrahamsen, A. R. Homogeneous Fluidization of Fine Powders Using Various Gases and Pressures. Powder Technol. 1978, 19, 133-136.

(15) Abrahamsen, A. R.; Geldart, D. Behaviour of Gas-Fluidized Beds of Fine Powders. Part I. Homogeneous Expansion. Powder Technol. 1980, 26, 35-46.

(16) Tabis, B.; Essekkat, A. Three-Phase Multi-Compartment Model for Fluidized-Bed Catalytic Reactors: Autothermicity and Multiplicity of Steady-States. Chem. Eng. Sci. 1992, 47 (2), 407-419.

(17) Walton, K.; LeVan, M. D. Consistency of Energy and Material Balances for Bidisperse Particles in Fixed-Bed Adsorption and Related Applications. Ind. Eng. Chem. Res. 2003, 42, 6938-6948.

(18) Chen, J. C.; Grace, J. R.; Golriz, M. R. Heat Transfer in Fluidized Beds: Design Methods. Powder Technol. 2005, 150, 123-132.

(19) Horio, M.; Nonaka, A. A Generalized Bubble Diameter Correlation for Gas-Solid Fluidized Beds. AIChE J. 1987, 33 (11), $1865-1872$.

(20) Mori, S.; Wen, C. Y. Estimation of Bubble Diameter in Gaseous Fluidized Beds. AIChE J. 1975, 21 (1), 109-115.

(21) Hilligardt, K.; Werther, J. Local Bubble Gas Hold-up and Expansion of Gas/Solid Fluidized Beds. Ger. Chem. Eng. 1986, 9, 215221.

(22) Yang, W.-C. Modification and Re-Interpretation of Geldart's Classification of Powders. Powder Technol. 2007, 171 (2), 69-74.

(23) Grace, J. R. Contacting Modes and Behaviour Classification of Gas-Solid and Other Two-Phase Suspensions. Can. J. Chem. Eng. 1986, 64 (3), 353-363.

(24) Werther, J. Fluidization IV, Kashikojima, Japan; Kunii, D., Toei, R., Eds.; Engineering Foundation: Kashikojima, Japan, 1983; p 93.

(25) Rowe, P. N.; Partridge, B. A.; Lyall, E. Cloud Formation around Bubbles in Gas Fluidized Beds. Chem. Eng. Sci. 1964, 19, 973-985.

(26) Sit, S. P.; Grace, J. R. Effect of Bubble Interaction on Interphase Mass Transfer in Gas Fluidized Beds. Chem. Eng. Sci. 1981, 36, 327-335.

(27) Kothari, A. K. Analysis of Fluid-Solid Heat Transfer Coefficients in Fluidized Beds; Illinois Institute of Technology: Chicago, 1967.

(28) Chen, J. C. Surface Contact-Its Significance for Multiphase Heat Transfer: Diverse Examples. J. Heat Transfer 2003, 125, 549-566.

(29) Baskakov, A. P.; Berg, B. V.; Vitt, O. K.; Filippovsky, N. F.; Kirankosyan, V. A.; Goldobin, J. M.; Maskaev, V. K. Heat Transfer to Objects Immersed in Fluidized Beds. Powder Technol. 1973, 8, 273-282.

(30) Lee, A.; Mebane, D.; Fauth, D. J.; Miller, D. C. A Model for the Adsorption Kinetics of $\mathrm{CO}_{2}$ on Amine-Impregnated Mesoporous Sorbents in the Presence of Water. Presented at the 28th International Pittsburgh Coal Conference, Pittsburgh, PA, 2011.

(31) Wen, C. Y.; Chen, L. H. Fluidized Bed Freeboard Phenomena: Entrainment and Elutriation. AIChE J. 1982, 28 (1), 117-128. 